\title{
Las renovaciones socialistas que no vencieron ${ }^{*}$
}

\author{
The socialist renovations that did not win
}

\author{
Mariana Perry*
}

\begin{abstract}
Resumen:
El presente artículo busca iluminar la complejidad y diversidad de las transformaciones teóricas y prácticas experimentadas por partidos políticos de izquierda luego del golpe de Estado de 1973. El análisis se realiza abordando la trayectoria histórica del partido socialista, su vínculo con el partido comunista y el tema del exilio como factor influyente en los distintos tipos de renovación política.
\end{abstract}

Palabras clave: Partido Socialista de Chile, renovaciones, oposición democrática, exilio

\begin{abstract}
This article seeks to illuminate the complexity and diversity of the theoretical and practical transformations experienced by political parties of the left after the coup d'etat of 1973 . The analysis is made addressing the historical trajectory of the socialist party, its link with the communist party and the issue of exile as an influential factor in the different types of political renovation.
\end{abstract}

Keywords: Chile Socialist Party, renovations, democratic opposition, exile

\section{Introducción}

La radicalidad del golpe de estado en Chile en 1973 generó múltiples quiebres que desataron profundos cambios en la realidad chilena. Para la izquierda en particular, ese 11 de septiembre, no significó solamente la necesidad de establecer estrategias prácticas de emergencia para sobrevivir, sino que, además, fue el punto de partida de sendos procesos de reflexión política que buscaron dar sentido e interpretar el cambio del escenario político en Chile.

La experiencia de la vulneración de derechos humanos por parte del régimen, el exilio, y la imposibilidad de participar activamente en la vida política chilena, llevó a muchos dirigentes políticos de izquierda a cuestionar los proyectos hasta entonces sustentados para hacer frente a la nueva realidad.

El camino recorrido por el socialismo chileno en este sentido adquiere una importancia trascendental. Desde su fundación, albergó diversas tendencias, por lo que su labor interpeló a amplios sectores políticos de la sociedad. Por esto mismo, los debates y cambios provocados por el golpe de estado al interior del socialismo afectaron de manera directa al mundo de izquierda en general. La realidad del Partido Socialista (PSCh) luego del golpe de estado; un partido escindido por el exilio y la persecución política al interior del país, la comunión directa en el exilio con realidades políticas diversas

${ }^{*}$ CONICYT/POSTDOCTORADO/3180014. Se agradece a CONICYT el apoyo a la investigación.

** Chilena. Doctora en Humanidades por la Universidad de Leiden. Profesora Investigadora, Instituto Historia, Facultad de Derecho y Gobierno, Universidad San Sebastián, Santiago marianaperryf@gmail.com 
propias de la Guerra Fría, y la relación con el resto de los partidos políticos chilenos, fueron determinantes para el devenir del partido hacia fines de 1970 y la década de 1980.

El objetivo principal del presente artículo es analizar los caminos recorridos por el PSCh luego del golpe de estado en Chile. En particular, se buscará identificar cómo las evaluaciones del período de la Unidad Popular, el golpe de estado y la realidad en el exilio, impactaron en las reformulaciones y transformaciones políticas del partido. Como eje de análisis se abordarán los elementos que determinan el proceso de Renovación en tanto hito determinante en las divisiones políticas al interior del partido y cómo su evolución, en consonancia con el desarrollo de los acontecimientos políticos en Chile y el mundo, reordena el espectro político de izquierda chileno y determina el carácter de la oposición al régimen militar. Para lo anterior, es necesario analizar la trayectoria histórica del socialismo chileno, pues se sostiene que las fragmentaciones ocurridas luego del golpe son un continuo dentro de la historia del partido. En la misma línea, se analizan ciertos hitos relevantes de la historia chilena en donde se evidencia la importancia de la relación entre comunismo y socialismo para la configuración del camino político tomado por el socialismo durante buena parte del siglo XX. Finalmente se abordará el proceso de reflexión política al interior del socialismo luego del golpe militar identificando un primer momento entre 1973 y 1979 en donde se buscó mantener la unidad del partido en una difícil convivencia signada por el exilio y la persecución, y un segundo momento, luego del quiebre de 1979, en donde una serie de procesos estallan al interior del socialismo dando lugar a variados procesos de renovación.

\section{Crisis y renovación: la multiplicidad de un proceso complejo}

El golpe de estado en Chile, en múltiples niveles, actuó como catalizador de una serie de procesos de reconfiguración político-social, que implicó cambios y trasformaciones profundas en la sociedad chilena. En la izquierda en particular, como se mencionaba, la crisis provocada por el golpe dio paso a una serie de cuestionamientos teóricos y prácticos que reconfiguraron de manera violenta el escenario político chileno. Como señala Valderrama, ${ }^{1}$ el golpe implicó una deconstrucción del sistema de representaciones desde donde la izquierda se reconocía, para reconstruir de otra manera un nuevo modelo de representación de la realidad en base a los nuevos desafíos presentados en la sociedad chilena tras los cambios instaurados luego del golpe.

Esta deconstrucción y posterior reconfiguración es explicada, desde la teoría, en que una crisis fuerte sumada a una percepción de fracaso, incentiva, más que cualquier otro hito, la búsqueda de nuevos referentes para hacer frente a una nueva realidad cambiante. ${ }^{2} \mathrm{La}$ idea que subyace es que el trauma y las experiencias de fracaso, obligan a aceptar que el ordenamiento del mundo -tal y como estaba definido- ya no hacen sentido, y se fuerza a la mente a considerar nuevas ideas para reordenar el entendimiento de la realidad. Según Nancy Bermeo ${ }^{3}$, las dictaduras latinoamericanas provocaron cambios cognitivos fundamentales y forzaron el replanteamiento de ideas bases del pensamiento político tales como; la naturaleza de los regímenes políticos, los enemigos o aliados, las metas y comportamientos en política.

En el caso chileno, Garretón y Espinosa, ${ }^{4}$ sugieren que el aprendizaje político experimentado por la oposición al régimen militar, luego del golpe de 1973, pasó por tres etapas esenciales. La primera

\footnotetext{
${ }^{1}$ Miguel Valderrama," Renovación Socialista y Renovación Historiográfica", PREDES Debates y Reflexiones. Aportes para la investigación social, Santiago de Chile, No.5, 2001, pp. 2-38.

2 Jennifer McCoy, "Political learning and redemocratization in Latin America", Paper presentado en el XIX Congreso Internacional del Latin American Studies Association, Washington DC, 1995.

${ }^{3}$ Nancy Bermeo, "Democracy and the Lessons of Dictatorship", Comparative Politics, No. 3, Vol. 24, Nueva York, 1992 , pp. 273-291.

4 Manuel A. Garretón y Malva Espinosa, "Chile: Political Learning and the Reconstruction of Democracy", En Jennifer McCoy (Ed.), Political Learning and Redemocratization in Latin America: Do Politicians Learn from Political Crises? Florida, North-South Center Press at University of Miami, 2000, pp. 37-71.
} 
aborda las causas del golpe militar y la dictadura. La segunda se refiere a los medios para desafiar y derrotar a la dictadura. Y la tercera concierne al aprendizaje de los actores mismos en su desempeño político durante la transición a la democracia. En las tres etapas, el aprendizaje no se manifestó en todos los actores por igual y dependió en gran medida del trasfondo intelectual, práctico, y en el destino del exilio, de cada actor político. Es decir, la reconstrucción luego de la crisis generada por el golpe, lejos de ser homogénea, presenta una multiplicidad de caminos por los que las distintas izquierdas recorren para rearmar sus proyectos políticos en contexto de dictadura y exilio. Las distintas interpretaciones sobre la experiencia de la Unidad Popular, la naturaleza del régimen, los errores cometidos, la influencia del contexto político del exilio, entre otros elementos, dan paso a decisiones político-estratégicas de muy distinto signo, lo que implicaría más bien hablar de renovaciones políticas dentro de la izquierda chilena post golpe.

Particularmente para el caso del socialismo chileno, Kenneth Roberts ${ }^{5}$ sostiene que la renovación del PSCh responde a tres crisis fundamentales que posibilitan el cambio. La primera, es una crisis de sentido o teleológica que obedece a una progresiva deslegitimación del socialismo como modelo material de la sociedad, para considerarlo como un modelo a conseguir en el marco democrático. La profundidad de la crisis del sentido genera a su vez una crisis en las estrategias, puesto que la nueva finalidad del socialismo requería otros medios para alcanzarlos. De ahí que el consenso y la búsqueda de nuevas alianzas políticas sean centrales para conseguir las hegemonías políticas que permitan el cambio. Tanto la crisis del sentido, como de estrategias conducirán a una tercera crisis en torno al agente del cambio.

A partir de dichas crisis fundamentales, surgen diversos caminos en base a énfasis y enfoques que marcan la diversidad del proceso. Por ejemplo, entre la literatura existente, se identifica una tensión entre los que hablan que la reconfiguración provocada por el golpe obligaba una necesaria desintegración del proyecto político de la UP, por considerar "que no está a la altura de las exigencias actuales" por ejemplo en Viera-Gallo, ${ }^{6}$ o en la misma línea, pero con otro enfoque, Clodomiro Almeyda sobre la Renovación sostuvo críticamente: "Por el camino de cuestionarlo todo y revisarlo todo se ha llegado al extremo de llegar a plantear la incompatibilidad entre la democracia y el socialismo, confundiéndose en este caso con los neoliberales que piensan que no puede haber democracia sin libertad económica y soberanía del mercado ". ${ }^{7}$ En contraposición hay quienes sostienen que en la Renovación hay un rescate de la identidad socialista, por ejemplo: Arrate ${ }^{8}$ y especialmente a través del rescate de la figura de Allende en Garretón. ${ }^{9}$

Para los comunistas, la renovación ocurrida luego del golpe y la represión tomó un camino distinto. La influencia soviética directa y la experiencia de la represión en Chile fueron centrales en el giro político que el partido tomó. Como resultado "se desvaneció el optimismo puesto en las posibilidades del tránsito institucional, y las esperanzas fueron puestas, en último término, en la violencia revolucionaria". ${ }^{10}$ Así Álvarez, ${ }^{11}$ sostiene que el aprendizaje del Partido Comunista de Chile (PCCh) a partir de la crisis generada por la derrota de la UP, los primeros años de experiencia en el socialismo real en el exilio y la represión al interior del régimen, "significó una profunda transformación a nivel teórico y cultura política en el PC". ${ }^{12}$ El aprendizaje, según Álvarez, estuvo dado por "una

\footnotetext{
${ }^{5}$ Kenneth Roberts, "Renovation in the Revolution? Dictatorship, Democracy, and Political Change in the Chilean Left", Working Paper, No. 203, Notre Dame, Helen Kellogg Institute for International Studies, 1994, pp. 1-36.

6 José Antonio Viera-Gallo, "Renovar la izquierda", Revista Chile América, Roma, No., 50-51, 1979, pp. 61-62.

7 Clodomiro Almeyda. "Entrevista a Clodomiro Almeyda. El legado de Allende es su llamamiento persistente a la unidad", Revista Chile América, No. 82-83, Roma, Octubre-Noviembre-Diciembre 1982, p.39.

${ }^{8}$ Jorge Arrate, El socialismo chileno: rescate y renovación, Barcelona, Ediciones del Instituto para un Nuevo Chile, 1983.

${ }_{9}^{9}$ Manuel A. Garretón Garretón, Las ideas de la renovación socialista. Sintesis y Balance. Material de Trabajo, Santiago, Flacso, 1987.

10 Tomás Moulián, “El Marxismo en Chile: Producción y Utilización”, José. J. Brunner, Martín Hopenhayn, Tomás Moulián, y Ludolfo Paramio (Eds.), Paradigmas de conocimiento y práctica social en Chile, Santiago de Chile, FLACSO, 1993, pp. 107-161, p.106.

11 Rolando Álvarez, La tarea de las tareas: luchar, unir, vencer. Tradición y renovación en el Partido Comunista de Chile (1965-1990), Santiago de Chile, Tesis Doctoral, Universidad de Chile, 2007, p. 293.

12 Idem.
} 
mirada laica de la política que estimaba que la elaboración teórica del accionar del PC debía estar conectada con el movimiento real de la lucha de clases y no atado a dogmas esclorizados". ${ }^{13}$ Este aprendizaje conllevó a cambiar la línea del PCCh y por tanto renovar su práctica y planteamiento político. Como sostiene Álvarez, más allá de una apreciación valorativa con respecto al giro, durante el período post golpe, el PCCh desarrolló un proceso que "se caracterizó en buscar nuevas formulaciones para la teoría y la praxis de la izquierda conservando la perspectiva de la sustitución del capitalismo", ${ }^{14}$ lo que condicionó el desarrollo de su política durante la década de 1980. Álvarez sostiene que la renovación del comunismo actuó en tres niveles: la incorporación de lo militar en la política; una democratización interna y un cambio en los objetivos estratégicos del partido orientado a unir socialismo y democracia. Sin embargo, dicho autor sostiene que la dirección del partido se resistió a aceptar algunos aspectos de esta renovación, particularmente la que tenía que ver con plantear críticas a la política de la Unión Soviética y a los socialismos reales y generar una mayor democratización al interior del partido. ${ }^{15}$

Los anteriores, son ejemplos de las Renovaciones más emblemáticas del período, sin embargo, al interior de todos los grupos políticos de izquierda se dieron cambios y transformaciones, más o menos profundas y redirecciones más o menos radicales, luego del golpe de estado. A pesar de ello, como se observa a lo largo del artículo, el devenir político social del Chile de los años ochenta sumado a los nuevos planteamientos políticos que se gestaron desde la oposición, dieron paso a que fuese la Renovación socialista la que prima por sobre las otras propuestas y la que direccione el rol del PSCh en la política chilena y el ritmo de la transición política hacia la democracia.

A continuación, se analiza la trayectoria histórica del socialismo con el objetivo de identificar aquellos hitos formativos de identidad que explican, en parte, la fragmentación ocurrida luego del 11 de septiembre de 1973.

\section{Trayectoria histórica del PSCh}

El presente apartado tiene tres objetivos específicos: identificar la naturaleza heterogénea del socialismo, comprobar la importancia central de la relación entre el PCCh y el PSCh para las formulaciones prácticas y teóricas del socialismo chileno y reconocer el rol que la política internacional jugó en la composición ideológica del PSCh.

La década de 1920 en Chile estuvo definida por las consecuencias de la crisis del salitre sobre la economía chilena, a lo que se sumó la crisis económica mundial del año 1929, que azotó fuertemente a Chile. Como respuesta, el Estado redujo el ya pequeño gasto público cimentando el camino para el surgimiento de diferencias sociales pronunciadas y la explosión de un descontento social que, desde la emergencia de la "cuestión social" en el cambio de siglo, venía moldeando la aparición de nuevos grupos políticos que desafiaban la representatividad de los partidos políticos tradicionales.

En paralelo, el PCCh había dejado de contar con el apoyo de la clase obrera que el Partido Obrero Socialista (POS) había detentado. La adhesión al comunismo internacional, las divisiones entre Trotsky y Stalin y la represión que sufrió el partido durante el período de gobierno de Carlos Ibáñez del Campo, contribuyeron al progresivo debilitamiento del PCCh. Esta debilidad condujo a la creación de una serie de movimientos inspirados en los principios socialistas que compartían la preocupación por la clase trabajadora y la desconfianza de la lealtad del PCCh hacia los lineamientos de la Komintern. ${ }^{16}$ Esta desconfianza se potenció cuando el PCCh decidió no apoyar a la República Socialista en 1932, un

\footnotetext{
13 Idem.

${ }^{14}$ Idem.

15 Idem.

${ }^{16}$ Benny Pollack, "The Chilean Socialist Party: Prolegomena to Its Ideology and Organization”, Journal of Latin American Studies, No.1, Vol. 10, Cambridge, 1978, p.117-152.
} 
gobierno de corta duración, compuesto por diversos miembros de variados grupos socialistas y de algunas ramas de las fuerzas armadas. ${ }^{17}$

El vacío dejado por los comunistas entre el electorado fue aprovechado por estos movimientos socialistas quienes, tras una prometedora votación en la elección presidencial de 1932, decidieron conformar un partido que los agrupara. Así se funda el PSCh en abril de 1933 por la fusión de la Orden Socialista, el PS Marxista, la Acción Revolucionaria Socialista y la Nueva Acción Pública. ${ }^{18}$

El PSCh se transformó, de esta forma, en punto de encuentro entre tendencias diversas, tales como: populistas, socialistas democráticos y marxistas anti-estalinistas, representantes de las clases medias y sectores populares. Grupos que lograron reunirse en torno a un programa concreto que buscaba la transformación del orden social y económico a través de la revolución. ${ }^{19}$ En la misma línea, Ricardo Yocelevzky, ${ }^{20}$ sostiene que el PSCh cumplió la función de "dar forma orgánica a diversas manifestaciones de integración de las clases medias y sectores obreros a la política nacional", dicha integración a la política sostiene Yocelevzky, fue clave para mantener la unidad dentro de la heterogeneidad.

Inicialmente la doctrina política tuvo un rol menor en el éxito que comenzó a recibir el reciente partido. A pesar de la circulación de documentos de alto contenido revolucionario, el discurso se complementaba con versiones más moderadas de representantes de un partido que reunió a distintos proyectos en uno, generando un pensamiento híbrido. Según Drake ${ }^{21}$ la ideología política fue puesta en segundo plano para favorecer promesas concretas que solucionaran demandas de las clases medias y bajas. Se prefirió un estilo directo y pragmático para capturar las masas en vez del intelectualismo de los comunistas. Debido a la composición heterogénea del partido, se buscó lograr la uniformidad ideológica en torno al programa político del socialismo, apoyándose en prácticas caudillistas. ${ }^{22} \mathrm{De}$ hecho, en sus inicios, las figuras de Marmaduque Grove, Eugenio Matte y Oscar Schnake personificaron el socialismo para muchos de sus seguidores y a la vez ejercieron una influencia trascendental en la organización y vida cotidiana del joven partido. ${ }^{23}$ Arrate y Rojas ${ }^{24}$ sostienen que, en el PS, los liderazgos carismáticos tienen el peso decisivo; rasgo que, junto con su conformación heterogénea, definirá los fraccionalismos y divisiones que acompañan al partido, especialmente luego del golpe de 1973, como se analiza en la siguiente sección.

En referencia al impacto de la política internacional, el PSCh, se posicionó rápidamente como un partido antifascista, lo que se expresó en enfrentamientos callejeros con miembros del movimiento nacista ${ }^{25}$ en Chile. En un documento realizado por el Comité regional del partido socialista de Santiago con ocasión del 6to aniversario del PSCh, titulado "No somos un partido más", con respecto a su orientación, Oscar Schnake definía al partido como "realista" por inspirarse más en la realidad nacional que en ideas universales. ${ }^{26}$ De este modo sostuvo:

\footnotetext{
${ }^{17}$ Julio Faúndez, Marxism and Democray in Chile. From 1932 to the fall of Allende, New Haven, Yale University Press, 1988.

18 Ver: Jorge Arrate y Eduardo Rojas, Memoria De La Izquierda Chilena, Tomo1, Santiago de Chile, Ediciones B Chile S.A, 2003.

19 Ver: Alfredo Riquelme, Rojo atardecer: el comunismo cbileno entre dictadura y democracia, Santiago de Chile, Centro de Investigaciones Diego Barros Arana, 2009.

${ }^{20}$ Ricardo Yocelevsky, "El Partido Socialista de Chile bajo la dictadura militar", Revista Foro Internacional, No. 105, vol.21, México D.F, julio-septiembre 1986, p. 105.

21 Paul Drake, Socialism and Populism in Chile, 1932-1952, Champaign, University of Illinois Press, 1978.

22 David Corkill, "The Chilean Socialist Party and The Popular Front 1933-41”, Journal of Contemporary History, No. 2/3, Vol. 11, 1976, p.261-273.

${ }^{23}$ Ver: Julio Jobet, El Partido Socialista de Chile. Tomo I. Santiago de Chile: Ediciones Prensa Latinoamericana, 1971.

24 Arrate y Rojas, op. cit.

${ }^{25}$ Esta clara y abierta posición anti fascista contrastó con el inmovilismo del PCCh que se explicaba por el Pacto Molotov-von Ribbentrop. Pacto que entre sus cláusulas contenía la no agresión mutua entre la Alemania Nazi y la Unión Soviética firmado en 1939. Pollack, op. cit., p.122.

26Ver: Arrate y Rojas, op. cit.
} 
Vamos impulsando la acción de todo un pueblo, el movimiento de un pueblo hacia su liberación, por eso queremos darle un contenido nacional que abarque nuestra manera de trabajar, gozar, sufrir y sentir, para hacer un pueblo nuevo en todas sus facetas. ${ }^{27}$

Esta postura nacionalista actuaba como una evidente reacción al internacionalismo doctrinario del comunismo y demostraba un énfasis revolucionario de refundación social desde un enfoque que buscaba interpretar la realidad nacional. A pesar de la crítica al PCCh, el PSCh reconocía al marxismo como un método para interpretar la sociedad y a la lucha de clases como la expresión de intereses de clase antagonistas. Es decir, el socialismo adoptó al marxismo como orientación ideológica pero no como dogma. ${ }^{28}$ Para el PSCh el conflicto de clase era el motor para el cambio, pues la revolución social era el objetivo último. La teoría sobre el desarrollo nacional apuntaba a que la clase trabajadora expulsara a la elite capitalista tanto nacional como extranjera. El método era que el Estado controlara la propiedad privada a gran escala para lograr el crecimiento económico y la justa redistribución. ${ }^{29}$ Esta visión del socialismo rechazaba tanto el reformismo de los modelos democráticos de Europa, como el comunismo totalitario de la Rusia Soviética. Ahora bien, a pesar de una marcada mirada nacionalista, el PSCh desde sus inicios, observó diversos y eclécticos referentes externos para marcar su formación. Al respecto, Góngora señala:

Tienen algo del americanismo del APRA, pero con un mayor número de ingredientes. Abarcan desde simpatizantes del trotzkysmo, o, mejor dicho, anti estalinistas, hasta simpatizantes de Tito; marxistas doctrinarios, pero no moscovitas; masones, hombres de una izquierda definida como actitud más que con una idea; violentistas junto a hombres que podrían haber sido ministros durante el régimen parlamentario". 30

La mayor influencia latinoamericana al PSCh fue incorporada por Eugenio Matte, quien imprimió la influencia del APRA y de su líder Víctor Raúl Haya de la Torre sobre el recién fundado partido. ${ }^{31} \mathrm{El}$ aprismo ejerció una influencia central en muchos movimientos de corte socialista pues sintetizó ideas socialistas y nacionalistas dando una orientación latinoamericanista que se vio reflejada en muchos movimientos que surgieron durante la misma época. De hecho, el PSCh se caracterizó por ser un partido político internacionalista, cuyo principal foco y meta estaba en lograr la libertad de los trabajadores de Latinoamérica. Grove, en el discurso de clausura del Primer Congreso General el 31 de diciembre de 1933 señaló:

Hasta ahora la economía americana ha servido al imperialismo internacional; al Partido socialista le corresponde arrojar del poder a los grupos directivos que no han sabido mantener nuestra independencia frente a los intereses extranjeros de la banca, la industria o el comercio. El trabajo de los americanos debe servir en primer lugar a los americanos mismos. ${ }^{32}$

Este antiimperialismo fue útil al PSCh pues logró canalizar las ideas socialistas y nacionalistas que habían estado al origen del movimiento y que eran, mayoritariamente, los pilares en los que descansaba la popularidad que adquirió el partido.

27 Citado en: Eduardo Devés y Carlos Díaz (Ed.), El Pensamiento socialista en Chile: antología, 1893-1933, Santiago de Chile, América Latina Libros, 1987, p.232-233.

28 Ver: Jobet, op. cit.

${ }^{29}$ Ver: Pollack, op. cit., y Drake, op. cit.

30 Mario Góngora, Ensayo histórico sobre la noción de Estado en Chile en los siglos XIX y XX, Santiago de Chile, Editorial Universitaria, 1986, p.240.

31 Para más detalle sobre la relación del movimiento formado por Eugenio Matte Hurtado y el Aprismo peruano ver: Fabio Moraga, "¿Un partido indoamericanista en Chile? La Nueva Acción Pública y el Partido Aprista Peruano (1931-1933)", Histórica, No. 2, Vol. XXXIII, 2009, p.109-156.

32 Jobet., op. cit., p. 87. 
El socialismo, por tanto, se conformó como un partido ecléctico lo que implicaba que las referencias ideológicas debían mantenerse abstractas para lograr retener las diferentes sensibilidades que componían el partido, el que se aglutinaba principalmente en torno a programas concretos y a líderes carismáticos que se conectaban directamente con las masas. Así Arrate y Rojas sintetizan al respecto:

Las propuestas ideológicas del naciente partido no siempre encontrarán una concreción fácil en la práctica de dirigentes y militantes. La vida interna socialista se caracterizará en los años siguientes por vivos debates que a veces conducen a graves dificultades internas (...) Otras veces el divorcio entre teoría y práctica que trasuntan esas concepciones originarias discursivamente tan "puras" llevará al PS a situaciones críticas". 33

A estas difíciles uniones ideológicas, se le suman las disputas por el liderazgo representativo de las diversas tendencias que componían el partido, lo que sin duda determinaron las posteriores escisiones del partido.

Ahora bien, así como el eclecticismo definió esta etapa fundacional del PSCh, la relación a veces cercana y a veces lejana con el PCCh, se transformó en un importante conformador de identidad para el socialismo chileno a lo largo de su historia. A continuación, se verán algunos ejemplos en la historia chilena sobre cómo influyó en los caminos tomados por el socialismo, su vinculación con el PCCh.

\section{Socialismo y Comunismo: tensión y distensión en una relación compleja}

El PSCh surgió, como se estableció, entre otras razones, por el espacio dejado por un POS que, al adherir al comunismo, había minimizado los nexos con las bases. Además, al ser su creación posterior al PCCh, su narración desde el origen tomó como referencia al comunismo. En algunas ocasiones para distanciarse por su vínculo con el comunismo soviético y en otras para acercarse y crear alianzas partidarias. Así, la relación con el PCCh marca determinantemente la identidad socialista y repercutió en sus propias divisiones. Un hito en esta línea es la creación del Frente Popular el año 1936.

Para marcar su descontento debido a las medidas económicas instaladas por el gobierno de Alessandri, las clases populares se organizaron en torno a masivas huelgas laborales, las que fueron fuertemente reprimidas. Como consecuencia, diversos grupos políticos de izquierda, entre ellos, comunistas y socialistas, se aliaron para hacer frente a las políticas del gobierno de Alessandri. ${ }^{34} \mathrm{La}$ alianza entre socialistas y comunistas se facilitó pues, desde 1935, el Komintern comenzó a defender la creación de alianzas con partidos "burgueses" para defender la democracia de la amenaza fascista. ${ }^{35}$ Además, el comunismo chileno, había iniciado una reflexión similar en torno a la necesidad de aliarse con partidos políticos de la burguesía nacional, para cumplir el objetivo de la revolución socialista, por lo que el dictamen de 1935 desde Moscú, vino a confirmar una política ya reflexionada por el comunismo chileno. ${ }^{36}$

A pesar de los factores nacionales e internacionales que abrieron al comunismo chileno a crear alianzas, aun persistían desconfianzas entre los líderes políticos socialistas. De hecho, en 1934 se constituye alrededor del PSCh el "Bloque de Izquierda", formado por radicalsocialistas (escindidos del radicalismo) y el Partido Democrático (escindido también y con posturas más moderadas, apoyando

\footnotetext{
33 Arrate y Rojas., op. cit., p.173-174.

34 Ver: Julio Faúndez, Marxism and Democracy in Chile. From 1932 to the fall of Allende, New Haven, Yale University Press, 1988.

35 Idem.

36 Ver: María Soledad Gómez, "Factores nacionales e internacionales de la política interna del Partido Comunista de Chile (1922-1952)", En Augusto Varas, Alfredo Riquelme y Marcelo Casals (Edits.), El Partido Comunista en Chile. Una historia presente, Santiago de Chile, Editorial Catalonia. 2010, p. 75-120. Rolando Álvarez, Desde las sombras. Una historia de la clandestinidad comunista (1973-1980). Tesis para optar al grado de Magíster, Santiago de Chile, Universidad de Santiago, 2001.
} 
incluso al gobierno de Alessandri). Dicho bloque se opone a la alianza con el PCCh. ${ }^{37}$ Los radicales que son fundamentales para el éxito posterior de la alianza, también se muestran recelosos de la alianza con comunistas. No obstante, el punto de inflexión que allanó el camino para la creación del Frente, se dio el año 1936 cuando el gobierno de Alessandri, -que para entonces había disuelto el congreso, censurado la prensa opositora, y apresado a varios líderes políticos de oposición- reprimió duramente una huelga de los empleados de ferrocarriles que exigían un aumento de sueldo. Dicha represión empujó la formación de la coalición en contra de Alessandri. ${ }^{38}$ Sumado a lo anterior, se vuelve a repetir la dinámica, cuando el año 1938, el gobierno de Alessandri reprimió severamente a los jóvenes nacistas que habían iniciado un fallido intento de golpe de estado, dando muerte a más de sesenta jóvenes apostados en el edificio del Seguro Obrero. ${ }^{39} \mathrm{El}$ manejo de la crisis y su cruento desenlace mermó el apoyo del candidato de Alessandri, Gustavo Ross, en las elecciones presidenciales de 1938, resultando elegido el radical Pedro Aguirre Cerda, representante del Frente Popular.

Si bien el Frente Popular logró mantenerse en el poder durante tres administraciones, la tensión de socialistas y radicales con la alianza con el comunismo no disminuyó. A modo de ejemplo, el año 1939 subrayó las distancias entre socialistas y comunistas, debido al apego del PCCh a la línea soviética en referencia al ya mencionado pacto Molotov-Von Ribbentrop, hecho que Arrate y Rojas señalan como "el hecho más grave para las relaciones entre los partidos Comunistas y Socialistas". ${ }^{40}$ Los comunistas, por su parte, fueron críticos de la dirección "socialdemocrata" a la que el PSCh llevaba el Frente Popular. Galo González, líder comunista, sostuvo que el liderazgo socialista de Oscar Schnake se había pasado "al campo del imperialismo" y lanzado "por la pendiente fascista del anticomunismo". ${ }^{41}$ Así, los socialistas se retiraron del Frente Popular en 1941, manteniendo la presencia de sus ministros en el gobierno. Esto, no sin divisiones internas, ya que mientras la directiva socialista promovía una campaña anticomunista (liderada por Oscar Schnake y Bernardo Ibáñez), el PS Trabajadores, fracción liderada por los llamados "incorformistas" apoyaba al bloque político, fracción que posteriormente se incorporó al partido comunista. Lo anterior muestra una evidencia más de la continua tensión que cruza la historia socialista en referencia a su vínculo con el comunismo chileno, que marcó fuertemente la realidad post golpe como se ve a continuación. Dichas tensiones saldrán a la luz de manera declarada durante el gobierno del tercer radical en el poder: Gabriel González Videla.

En línea con la alianza del Frente Popular, y los buenos resultados electorales que había generado, el Frente se preparaba para un tercer gobierno radical con González Videla a la cabeza. Sin embargo, y en un contexto internacional de creciente anticomunismo, representantes de partidos conservadores, y secciones del radicalismo y el socialismo, habían buscado maneras de frenar la injerencia del PCCh que, para la elección municipal de 1947, se había convertido en el tercer partido con más votación en el país.

El socialismo, que no formaba parte del gobierno, se encontraba en un importante proceso de reflexión interna producto de los deficientes resultados que habían obtenido en las últimas elecciones. Las relaciones entre las diversas tendencias del socialismo debilitado y el comunismo están en un punto de alta tensión, que se traduce en crudos enfrentamientos a nivel sindical. A su vez, el socialismo está dividido entre una mayoría dirigida por Eugenio González y Raúl Ampuero y las corrientes anticomunistas de Bernardo Ibáñez y Juan Bautista Rossetti.

A los pocos meses de iniciado su gobierno, y acusados de incitar el desorden social, González Videla, excluyó a los comunistas de su gabinete. La primera medida del nuevo gabinete formado por

\footnotetext{
37 Ver: Arrate y Rojas, op. cit.

38 Ver: Corkill., op. cit.

39 Para mayor detalle ver: Marcus Klein, La Matanza Del Seguro Obrero: (5 De Septiembre De 1938), Santiago de Chile, Globo Editores, 2008.

40 Arrate y Rojas, op. cit., p.213.

41 Arrate y Rojas, Ibid., p. 216.
} 
radicales, liberales, socialistas, conservadores y demócratas, fue introducir la Ley Maldita ${ }^{42}$ para prohibir el PCCh en septiembre de 1948. Con esta ley, se inauguraba una política anticomunista estatal que buscó "eliminar jurídica y políticamente a los comunistas". ${ }^{43}$

En reacción a la Ley Maldita, el socialismo se dividió entre aquellos líderes que apoyaban al diputado Bernardo Ibáñez en su política anticomunista, denominados Partido Socialista de Chile y los que no (como Salvador Allende, Marmaduque Grove y Carlos Alberto Martínez, entre otros), formando el Partido Socialista Popular. ${ }^{44}$

Las divisiones se mantuvieron cuando, en el congreso de 1951, el Partido Socialista Popular declaró a Carlos Ibáñez del Campo como su abanderado en las próximas elecciones presidenciales. Esto hizo que Salvador Allende y José Tohá renunciaran al PSP y se unieran al Partido Socialista de Chile, quien, en conjunto con el proscrito PSCh, respaldaron la candidatura de Allende. Sin embargo, ya en 1953, los representantes del PSP que contaban con puestos senatoriales y en la cámara de diputados, abandonan el gobierno de Ibáñez por su giro hacia la derecha y plantean la necesidad de crear una alianza entre las fuerzas de izquierda. Durante ese período, el comunismo, específicamente el año 1952, en su novena conferencia, había dado forma a la línea política del "Frente de Liberación Nacional" 45 que dirigió la política del partido en las décadas siguientes, privilegiando una actitud unitaria con el PSCh. ${ }^{46}$ Por su parte, en 1955, el PS Popular anunció su estrategia de "Frente de Trabajadores" 47 en el XVI Congreso, en donde denuncia los acuerdos con partidos "burgueses", proponiendo alianzas solo con partidos obreros y la CUT, acercándose al comunismo. Lo anterior, conduce, en 1956, a la creación del Frente de Acción Popular (FRAP).

$\mathrm{Al}$ momento de formación del FRAP el socialismo aún no se había unificado. ${ }^{48} \mathrm{~A}$ dicha división se sumaba la búsqueda de referentes ideológicos internacionales que sirvieran de apoyo a las decisiones de ambos partidos. $\mathrm{Al}$ respecto Ernst Halperin caracteriza al socialismo chileno de la época como de una "extrema susceptibilidad a modas políticas importadas ya sea de otros continentes como de otros países de América Latina". ${ }^{49}$ Como señala Ulianova ${ }^{50}$, "la diversidad interna del socialismo chileno se reflejaba en sus vínculos internacionales". Por un lado, el PS de Chile, en alianza electoral con los comunistas desde 1952, se insertó en las redes internacionales de sus aliados. En este marco Salvador Allende junto a una delegación socialista viajó a China y manifestó su admiración llegando incluso a presidir el Instituto Cultural Chileno-Chino. ${ }^{51}$ El PSP, por otro lado, miró con inspiración la

42 Para mayor detalle ver: Carlos Huneeus, La guerra fría chilena. Gabriel González. Videla y la Ley Maldita. Santiago de Chile, Random House Mondadori, 2009.

${ }^{43}$ Huneeus, Ibid., p. 195.

${ }^{44}$ Andrew Barnard, "Chile", En Leslie Bethell y Ian Roxborough (Edits.), Latin America between the Second World War and the Cold War 1944-1948 (66-91), Cambridge, Cambridge University Press, 1992.

45 El Frente de Liberación Nacional, se basaba en la concepción de una revolución de dos etapas. La primera libraría la economía del imperialismo extranjero y de la oligarquía, preparando el terreno para el socialismo, manteniendo alianzas con partidos representantes de la fuerza laboral e incluso de la burguesía. En la segunda etapa, los partidos de trabajadores conquistarían el poder iniciando la transición al socialismo.

46 Ver Luis Corvalán Márquez, "Las tensiones entre la teoría y la práctica en el Partido Comunista en los años 60 y 70 ”, En Jorge Rojas y Manuel Loyola (Eds.), Por un rojo amanecer: hacia una bistoria de los comunistas chilenos, Santiago, The Author, 2000, p. 227-244.

${ }^{47}$ Estrategia influenciada ideológicamente por las posturas de Trotsky con respecto a los países subdesarrollados, se basó en el rechazo de que la burguesía tenía un rol que jugar en el proceso hacia la revolución socialista. Por esto, los socialistas defendían una alianza de intelectuales con trabajadores manuales, quienes, bajo el liderazgo del Partido Socialista, lograrían la revolución nacional y democrática en contra del imperialismo y la oligarquía. Asimismo, rechazaban la estrategia de dos etapas de los comunistas, defendiendo un solo proceso revolucionario continuado. $\mathrm{Al}$ respecto, ver: Faúndez, op. cit.

48 La unificación del socialismo se desarrolló en 1957 y concordó con la estrategia del "Frente de Trabajadores", en la incapacidad de la burguesía para lograr el desarrollo nacional, y en la necesidad de mantener la alianza con los comunistas. Así, socialistas y comunistas eligieron a Salvador Allende como candidato presidencial para la elección de 1958, la que, a pesar de no ganar, sirvió para demostrar la factibilidad real de un triunfo democrático de izquierda.

${ }^{50}$ Ulianova., op. cit., p. 238.

51 Ulianova., Ibid., p.255. 
experiencia en la Yugoslavia de Tito. Luego del "Discurso secreto" de Khrushchev y su viaje a Belgrado en 1955, la admiración por Tito y por su socialismo autónomo e independiente de la influencia soviética, creció fuertemente dentro del socialismo chileno..$^{52}$

La tendencia "titoísta" en esta línea del socialismo, generó grandes tensiones con el PCCh cuando éste último respaldó el quiebre de la Unión Soviética con Yugoslavia y su invasión a Hungría en 1956. ${ }^{53}$ El titoismo perdió peso dentro del socialismo durante los 1960, particularmente frente a la avalancha que significó la influencia de la Revolución cubana. ${ }^{54}$

La revolución cubana tuvo un rol de importancia dentro de la izquierda internacional y particularmente la izquierda chilena, pues planteó serios desafíos doctrinarios y reordenó el panorama ideológico del momento. El PCCh, por un lado, si bien celebró el desarrollo de los eventos en Cuba, buscó distanciarse de la estrategia violenta para alcanzar objetivos, especialmente luego de que en el último congreso del Partido Comunista Soviético se instauró la estrategia de la vía pacífica al socialismo. ${ }^{55}$ Para el socialismo, en cambio, la revolución cubana prontamente se convirtió en un modelo a seguir debido a su propuesta original, su énfasis latinoamericanista y su impulso revolucionario. $.^{56},{ }^{57} \mathrm{La}$ apreciación de las implicancias de la revolución cubana para Chile fue otro factor divisorio entre comunismo y socialismo, éste último "menos crítico de Cuba en el discurso ideológico". 58

En un análisis retrospectivo, Tomás Moulián caracteriza esta época del socialismo chileno, particularmente entre 1958 y 1979, como de un progresivo proceso de leninización y "de abandono progresivo de la perspectiva teórica original, de carácter nacional-popular". ${ }^{59}$ Leninización que no solo alcanzó a sus bases, sino también a las elaboraciones teóricas del liderazgo, siendo Carlos Altamirano "el más nítido ejemplo de esta línea". ${ }^{60}$

En suma, los focos de tensión entre socialismo y comunismo se articulaban en dos ejes centrales. Por un lado, la lealtad del comunismo chileno hacia las directrices de Moscú, especialmente la opción por la estrategia de la vía pacífica chocaba con el socialismo, el que veía la dominación soviética de la III internacional como un atentado en contra de los postulados marxistas, pues privilegiaba los intereses de seguridad nacional de los Estados del bloque del Este, por sobre los intereses históricos de la clase trabajadora. ${ }^{11} \mathrm{La}$ segunda acusación sobre la vía pacífica se encontraba en que los socialistas miraban con desconfianza lo que denominaban "democracia burguesa". Al respecto, Raúl Ampuero en la conferencia "Reflexiones sobre la revolución y el socialismo", de 1961 acusaba que la burguesía latinoamericana no lideraría el proceso revolucionario debido a que estaba directamente involucrada

\footnotetext{
52 Ver: Pollack, op. cit.; Ulianova, op. cit., y Joaquín Fermandois, La Revolución Inconclusa. La izquierda cbilena y el gobierno de la Unidad Popular. Santiago de Chile, Centro de Estudios Públicos, 2013.

53 Tanto el PSP como el PS de Chile condenaron la intervención soviética en Hungría.

54 Ver: Halperin, op cit.

55 Este distanciamiento también es abordado por Miles Wolpin, quien señaló que "la experiencia cubana entusiasmó más moderadamente a los líderes comunistas [que a los socialistas]. El estilo carismático e impulsivo de Castro, y sus orígenes ortodoxos social democráticos, reforzaban las reservas de los comunistas chilenos" Miles Wolpin, "La influencia internacional de la Revolución Cubana: Chile, 1958-1970”, Foro Internacional, Vol. 12, No, 4 (48), Colegio de México, 1972, pp. 453-496, p. 474.

56 Ver: Arrate y Rojas, op. cit.

${ }^{57}$ Luis Ortega matiza la influencia de la revolución cubana señalando que ésta se sumó a un proceso de radicalización del PSCh que se encuentra con fuerza desde el Congreso de 1956, en donde un amplio sector del PSCh ante las crisis partidistas, abandona la política de alianzas con partidos burgueses que el partido había esgrimido hasta entonces. Además, Ortega sitúa la influencia de la revolución cubana en un mismo lugar de importancia que el cisma chino-soviético. Luis Ortega "La radicalización de los socialistas de Chile en la década de 1960", Revista Universum, No. 23, vol.2, Talca, 2008, pp.152-164.

58 Arrate y Rojas, Ibid., p.335.

59 Tomás Moulián, "Evolución histórica de la izquierda chilena. Influencia del marxismo", FLACSO Documento de Trabajo, No. 139, pp.1-54, 1982, p. 29.

${ }^{60}$ Marcelo Casals, El alba de una revolución. La izquierda y el proceso de construcción estratégica de la "vía chilena al socialismo" 1956 - 1970, Santiago de Chile, LOM Ediciones, 2009, p. 191.

${ }^{61}$ Ver: Faúndez, op. cit.
} 
con los intereses de los poderes imperialistas. Señaló también, en una clara crítica al comunismo, "que sería un pecado de leso optimismo el suponerla [la violencia] ajena a las tradiciones de nuestra clase dominante y una ingenuidad imperdonable incurrir en la idealización de los instrumentos electorales". ${ }^{62} \mathrm{~A}$ lo anterior, los comunistas respondían que su defensa de la vía pacífica se derivaba de la confianza en la posibilidad de introducir cambios revolucionarios con el apoyo del movimiento masivo sin tener que recurrir a la lucha armada.

Las tensiones entre socialistas y comunistas se repetían al interior del PSCh, el que, por un lado, experimentaba una progresiva radicalización como señalan Moulián y Ortega, y por otro, mantenía su adhesión a pactos electorales con el resto de los partidos de izquierda.

La tercera derrota de Salvador Allende el año 1964, los reordenamientos en el seno de la izquierda y el desafío DC, actuaron como catalizador dentro del socialismo chileno, radicalizando las posturas que, según Ortega, es posible identificar desde la década de 1950.63 Ejemplo de esto se dio con el X Congreso General Ordinario del PSCh del año 1964 en Concepción, en donde una sección juvenil expresó públicamente su rechazo a aceptar la autoridad del Comité Central por "discrepancias doctrinarias" separándose del partido para formar el Movimiento de Izquierda Revolucionaria (MIR) al año siguiente. ${ }^{64} \mathrm{El}$ XXI Congreso de 1965 en Linares actuó como "momento decisivo en la trayectoria socialista hacia una concepción insurreccional" 65 pues, se radicalizó la propuesta teórica del socialismo, preparando el camino para la realización del XXII Congreso, realizado en Chillán en noviembre de 1967, en donde el partido se declara marxista leninista y declara como inevitable y legítima la "violencia revolucionaria" como un medio para obtener el poder político y económico.

Ahondando la contradicción interna, y viendo que la no participación dentro del pacto electoral, privarían al socialismo de jugar un rol fundamental dentro de la política nacional, es que el partido decidió -no sin contradicciones internas- incorporarse a la alianza de la Unidad Popular en miras a la elección presidencial de 1970. Así, el socialismo en la práctica aceptó la vía electoral, pero ideológicamente mantuvo su creencia en la inevitabilidad de la vía armada. ${ }^{66}$

Los 3 años que duró el gobierno de la Unidad Popular, estuvieron marcados por una profundización en las divisiones internas tanto dentro del PSCh como dentro de otras agrupaciones políticas que sucumbieron a la polarización política que marcó el período. El delicado equilibrio al interior del socialismo se resquebrajó entre una corriente democrática liderada por Salvador Allende, y una corriente liderada por Carlos Altamirano que "insiste en la necesidad de destruir el Estado burgués y posee una concepción instrumental de la democracia". ${ }^{67}$ Esta última, fue la predominante entre los socialistas de la década de 1960, manteniéndose así durante todo el gobierno de la UP, lo que conllevó a constantes tensiones y enfrentamientos con el PCCh y con el propio presidente Allende.

Entre las demás agrupaciones, también se generaron divisiones producto de las tensiones ideologías que convivían en el proceso de la UP. El MAPU, (agrupación escindida de la Democracia Cristiana el año 1969, que decidió apoyar la candidatura de Salvador Allende en la elección de 1970), se dividió entre una opción moderada, cercana al PCCh y al liderazgo de Allende, y una opción más radical, que abandonaba su raíz cristiana para abrazar el marxismo leninismo que a su vez, se distancia del gobierno de Allende para optar por una estrategia armada de defensa de la revolución. ${ }^{68}$

\footnotetext{
${ }^{62}$ Julio Jobet, El Partido Socialista de Chile. Tomo II, Santiago de Chile, Ediciones Prensa Latinoamericana, 1971, p. 89.

${ }^{63}$ Ortega, op.cit.

${ }^{64}$ Ver: Joaquín Fernández, Álvaro Góngora y Patricia Arancibia (Eds.), Ricardo Núnę: Trayectoria de un socialista de nuestros tiempos, Santiago de Chile, Ediciones Universidad Finis Terrae. 2013.

65 Ortega, op.cit., p. 157.

66 Ver: Faúndez, op. cit.

${ }^{67}$ Jorge Vergara, “El pensamiento de la izquierda chilena en los sesenta. Notas de investigación”, En Augusto Varas, Alfredo Riquelme y Marcelo Casals (Edits.), El Partido Comunista en Chile. Una bistoria presente (185-226), Santiago de Chile, Editorial Catalonia Ltd, 2010, p. 203.

68 Para un completo estudio sobre los devenires del MAPU ver: Cristina Moyano, La seducción del poder y la juventud. Una aproximación desde la historia a la cultura politica MAPU 1969-1973. Tesis de Magíster, Santiago de Chile, Universidad de Santiago de Chile, 2002.
} 


\title{
Golpe y exilio
}

El golpe de estado el 11 de septiembre de 1973, desató una serie de crisis tanto prácticas como ideológicas que afectaron profundamente las fuerzas políticas de izquierda en Chile, quienes fueron víctimas de una severa represión por parte del régimen militar que se instaló en el poder.

El exilio, fue una de las principales herramientas utilizadas por el régimen para excluir a la oposición. Si bien no hay claridad en torno a los números totales del exilio, debido a que no todas las personas salieron por los canales establecidos por el régimen, Norambuena ${ }^{69} \mathrm{en}$ base a antecedentes elaborados por la Vicaría de la Solidaridad, estima que entre 1973 y 1980 habrían salido del país 408.000 personas.

Las características de los exiliados marcaron profundamente la naturaleza de la actividad política que se desarrolló en los distintos destinos del exilio. El régimen militar, exilió a estructuras partidarias prácticamente completas facilitando la proyección de la organización y la actividad política de denuncia en el escenario del exilio, conformando una comunidad políticamente comprometida. No obstante, la organización no fue ni inmediata ni fácil. La política chilena para 1973 había llegado a un grave punto de polarización que derivó en un alto grado de fragmentación entre las diferentes fuerzas políticas existentes, especialmente dentro de la izquierda. El golpe de estado no significó la moderación de estas diferencias, llevando a que los primeros años en el exilio estuviesen marcados por divisiones al interior de la ya atomizada izquierda chilena, la que corría en paralelo al activismo político en contra del régimen de Pinochet.

Esta crisis se complementó, a su vez, con las lecturas que el mundo progresista desarrollaba de los acontecimientos en Chile. Lecturas que permearon en las reflexiones políticas de la comunidad chilena en el exilio. Como nunca, los partidos políticos de izquierda en el exilio se relacionaban en masa y de manera directa con instituciones, personas e ideas en circulación que tenían sus propias conclusiones del golpe, por lo que el destino geográfico del exilio determinó profundamente la dirección que las reflexiones que los mismos partidos políticos chilenos en el exilio desarrollaban sobre su realidad. ${ }^{70}$ Así, un protagonista de la época distingue tres espacios según el país de acogida para comparar las distintas experiencias en el exilio:

\begin{abstract}
América Latina, Europa occidental y Europa del Este, sin considerar otras realidades particulares como Estados Unidos, Canadá y Australia. Con el tiempo surgirán de esa matriz exiliados de muy distinto tipo. Efectivamente la residencia prolongada en cualquiera de aquellos sitios generaría un proceso imperceptible (...) lo que se consideraba propio, se iría desdibujando ante el empuje de lo ajeno. Y algo de lo ajeno comenzaría a ser propio. ${ }^{71}$
\end{abstract}

En términos generales, los socialistas y líderes de la UP se establecieron en Berlín; los comunistas en Moscú, el MIR entre La Habana y París; y los MAPU en Italia al igual que la Izquierda Cristiana (IC) y en menor medida representantes del PDC una vez que pasaron a la oposición del régimen.

Los primeros análisis que se hicieron -en su mayoría-, continuaron las líneas ideológicas previas al golpe, cuya característica principal era atribuir culpas cruzadas sobre el fracaso de la UP. Una reflexión abocada al proceso interno de la UP, no se abordó en un primer

\footnotetext{
${ }^{69}$ Carmen Norambuena, "Exilio y retorno. Chile 1973-1994”, En Mario Garcés y Myriam Olguín (Edits.), Memoria para un nuevo siglo: Chile, miradas a la segunda mitad del siglo XX, Santiago de Chile, LOM Ediciones, 2000.

${ }^{70}$ Ver tesis doctoral de la autora. Mariana Perry, La dimensión internacional del pensamiento político chileno. Aprendiraje y transferencia en el exilio, Leiden, tesis para optar al grado de Doctor, Universidad de Leiden, 2016.

${ }^{71}$ Jorge Arrate, Pasajeros en tránsito, Santiago de Chile, Catalonia, 2007, p. 49-50.
} 
momento. ${ }^{72}$ Asimismo, las razones iniciales que se atribuían al golpe se complementaban con las lecturas que los partidos políticos de la UP, hacían sobre la naturaleza del recién instalado régimen militar; el que se creía de corta duración considerando la larga trayectoria democrática y republicana chilena.

El desarrollo de las reflexiones políticas del PSCh en el exilio es paradigmático para toda la historia política chilena, pues sus propios debates afectaron directamente el devenir del resto de los partidos políticos. Como se estableció en la sección anterior, el PSCh a lo largo de su historia, aglutinó de manera más o menos armoniosa, distintas tendencias políticas, por lo que la crisis vivida post golpe interpeló a variadas tendencias de la política chilena de la época. A lo anterior, se sumó que la espectacularidad de los cambios provocados por sus reflexiones desatadas por el golpe, retrataron fielmente la realidad heterogénea del partido.

Sucedido el golpe, el PSCh, al no tener una línea ideológica clara y permanente en el tiempo, no tenía una red internacional institucionalizada que respaldara su acción, como sí la tuvo el PCCh, por ejemplo. No obstante, la progresiva leninización que había experimentado el PSCh desde los 1960, y su definición como partido marxista-leninista, había acercado al partido en algunos aspectos a los países del este de la cortina, desde donde vinieron los primeros ofrecimientos concretos de apoyo tanto financiero como operacional para instalar en la capital de la República Democrática de Alemania el comité central del PSCh en el exilio. ${ }^{73}$

En escenario alemán, la dirección exterior con Carlos Altamirano a la cabeza mantuvo, en un primer momento, las reflexiones desarrolladas durante la UP. Ejemplo de ello, son las declaraciones de Altamirano en una reunión realizada en Italia en 1975 en donde sostuvo que la dictadura estaría aislada pero no caería por una falta de oposición organizada, por lo que abogaba por la "radicalización de la lucha antifascista", por "acumular más fuerzas que el fascismo y emplear todas las formas de lucha", recalcando que en la fase superior del proceso, "seguramente formas de lucha armada constituirán el factor decisivo en la victoria final". ${ }^{74}$ Asimismo, a la línea del socialismo post golpe, se le agrega la directa influencia del Partido Socialista Unificado de Alemania (PSUA). La naturaleza jerarquizada de la sociedad de recepción y el alto control ideológico que el PSUA ejerció sobre los exiliados se vio reflejado también en el tenor y dirección de los debates en el exilio, e incidieron, como se analiza más adelante, en la crisis del PSCh que condujo a su división el año 1979. Como ejemplo de la gravitación del contexto del exilio, Benny Pollack y Hernán Rosenkranz-Schikler, sostienen que el financiamiento provisto por la RDA al PSCh explicaba la predominancia de la Dirección Interior por sobre la Coordinadora Nacional de Regionales al interior de Chile, a pesar de la reticencia de Altamirano en esta elección. ${ }^{75}$

Con respecto al debate al interior del propio partido, es necesario abordar uno de los primeros documentos de reflexión de importancia luego del golpe, conocido como el

\footnotetext{
72Patricio Silva, "Social Democracy, Neoliberalism and Ideological Change in the Chilean Socialist Movement, 1973-1992", en XVII Congreso Internacional LAS A, California, 1992.

${ }^{73}$ Ver: Ulianova, op. cit.

${ }^{74}$ Carlos Altamirano en Chile-América, No6-7, Roma, 1975, p.33. Citado en Olga Ulianova, "Relaciones internacionales y redefiniciones en el socialismo chileno, 1973-1979”, Revista Irquierdas, No., 4, pp. 1-30, 2009, p.7.

75 Otro ejemplo, es la denominación como "fascista" de la dictadura militar que recorrió todo el desarrollo teórico de los partidos de izquierda y en general parece haber sido utilizado funcionalmente para apelar a la memoria colectiva en su asociación con las dictaduras europeas de la década del 1930 y 1940. Benny Pollack y Hernan Rosenkranz, Revolutionary social democracy: the Chilean socialist party, Nueva York, St. Martin's Press, 1986, p.189.
} 
Documento de marzo. ${ }^{76}$ Desarrollado por la 'Dirección Interior' en 1974, dicho documento en términos generales retomó los planteamientos del PSCh durante la UP pero a través de sus evaluaciones del proceso, se acercó de manera más evidente al discurso del bloque soviético, ${ }^{77}$ ya que buscó plantear una reconstrucción del partido en una organización de tipo pro comunista. ${ }^{78}$ Esto coincide con el temprano "énfasis de cubanos y alemanes de conservar y profundizar la unidad entre socialistas y comunistas", ${ }^{79}$ de hecho, al respecto, el documento señalaba la importancia de la unidad antifascista y "del rol dirigente de la clase obrera en el proceso", responsabilidad que recaía en los partidos socialistas y comunistas. Erich Honecker en una entrevista realizada el 10 de octubre de 1974, hablaba de los problemas suscitados al interior del PSCh y aludía a sus desavenencias con el PCCh, concluyendo que la unidad PSChPSCh debía ser el eje del Frente Antifascista. ${ }^{80}$ En el mismo sentido, Jorge Arrate señalando su reticencia a que los socialistas participaran en las escuelas de cuadros de los comunistas sostuvo: "yo estoy convencido de que el proyecto que tenían los alemanes era armar un solo partido que era su propia experiencia" 81 .

Particularmente, el "Documento de marzo", se enfocaba en, por un lado, culpar a la dirección del partido por no haber sido capaz de "articular y combinar el ejercicio de todas las formas de poder con que contaba el movimiento popular". Al respecto criticaba directamente al partido comunista por "magnificar la posibilidad de una vía pacífica, lo que redundó en ilusionismo y en errores fatales de apreciación del carácter de clase de las instituciones democrático-burguesas". Asimismo, criticaba a los "infantilistas de izquierda" que ponían la cuestión del enfrentamiento como "tema único, primero y último de la lucha de clases". Dichas críticas revelaban claramente las distintas posiciones al interior del partido. Por otro lado, y a pesar de las críticas, mantenía la necesidad de aliarse con los comunistas e incluso mencionaba la "orientación estratégica" de unir a "todas las clases y capas del pueblo que tienen contradicciones objetivas con los enemigos fundamentales" a través de un frente táctico antifascista incluyendo a partidos de centro como la DC para hacer frente a la dictadura, postura, como se señaló, fuertemente apoyada por líderes del este y de Cuba. En dicho frente, debía prevalecer la hegemonía de la clase obrera puesto que luego de superada la dictadura, sería la clase obrera la que debía prevalecer por sobre las capas medias. Agregaba el

\footnotetext{
${ }^{76} \mathrm{El}$ nombre completo del documento es: $\mathrm{Al}$ calor de la lucha contra el fascismo, construir la fuerza dirigente del pueblo para asegurar la victoria!. Documento extraído del sitio web http.www.socialismo-chileno.org, visitado en septiembre de 2015.

77 Ulianova atribuye este acercamiento a que los dirigentes de la Dirección Interior habían sido formados en la URSS durante los 1960. Olga Ulianova, "La Unidad Popular y el golpe Militar en Chile: percepciones y análisis soviéticos", Estudios Públicos, No. 79, 2000, pp. 83-171.

${ }^{78} \mathrm{La}$ Dirección Interior se auto designó como líder del partido a pesar de que el comité central había sido designado en el Congreso de La Serena de 1971. Esta disputa por el poder, legitimada para algunos por representar a los sobrevivientes del partido en el interior, representaba una clara facción dentro del socialismo, compuesta por la llamada Brigada Revolucionaria, también conocida como los Elenos, quienes emergen como movimiento dentro del partido por su apoyo a las luchas de liberación desarrolladas por el Che Guevara en Bolivia. Defendían la reformulación del partido bajo una estricta disciplina al modelo leninista, en donde la alianza socialista-comunista era considerada central para cualquier intento de política radical en Chile. Pollack y Rosenkranz, op. cit., p. 186-187. Conocida era la disputa entre este grupo y el liderazgo de Carlos Altamirano durante el período de la UP debido a las políticas radicalizadas de Altamirano que, según ellos, desperfilaba el proyecto de la UP. Ver también: Mauricio Rojas, La Renovación de la izquierda chilena durante la dictadura, Santiago de Chile, Piso Diez Ediciones, 2017.

${ }^{79}$ Ulianova 2014, op. cit., p. 305.

${ }^{80}$ Citado en Olga Ulianova, "La nueva inserción internacional del comunismo chileno tras el golpe militar", En Alfredo Riquelme y Tania Harmer (Edits.), Cbile y la Guerra Fría global, Santiago de Chile, RIL Editores, 2014, 273-315, p. 305.

81 Citado en María de los Ángeles Vargas y Lucila Díaz, Del golpe a la división. Historia del Partido Socialista 1973-1979. Tesis de Licenciatura, Santiago de Chile, Universidad ARCIS, 2007, p.142.
} 
documento, la necesidad de la aplicación "consecuente y creadora del marxismo-leninismo". En referencia a la estrategia "más probable de derrocamiento de la dictadura" es "la insurrección armada, definida por Lenin como 'aspecto particular de la lucha política"'.

Las reflexiones contenidas en el "Documento de marzo" concitaron reacciones de las distintas fracciones del PSCh tanto dentro como fuera de Chile y marcó la pauta de la discusión política en este primer período. Desde "la izquierda" de la Dirección Interior se criticó, por una parte, la falta de una estrategia militarizada de la UP y por otra, criticó el planteamiento de crear alianzas con partidos "burgueses" como la DC. Esta línea estuvo representada desde el interior por la Coordinadora Nacional de Regionales (CNR), que, en contraste con la Dirección Interior, rechazaba la unión con los comunistas, proponiendo en su lugar una alianza con el MAPU, el MIR y la IC con el objeto de crear un "Polo revolucionario", siendo rol del PSCh ser la vanguardia del proletariado. ${ }^{82}$ Para ello, sostenía la CNR: "debemos utilizar el leninismo como guía para la reconstrucción partidaria, la aplicación irrestricta de sus normas sin aceptar presiones exteriores-burocráticas". 83 Sumado a las diferencias en el plano de las ideas, el socialismo se vio también presa de luchas intestinas en relación con quien ostentaba la legitimidad en la dirección del partido. Entre abril y mayo de 1975 se realiza un pleno en La Habana con representantes del exilio y del interior. En esa instancia y con opiniones divididas, se otorgó legitimidad a la Dirección Interior por sobre la CNR. No obstante, el mismo año, el régimen detiene y desaparece al liderazgo de la Dirección Interior, poniendo nuevamente en cuestión la legitimidad del poder al interior. Por lo mismo, Altamirano redacta una carta en junio de 1977: "Mensaje a los socialistas de Chile" 84 respaldando a la Dirección Interior frente al CNR, al que critica por incurrir "en un subjetivismo maximalista poco coherente" ${ }^{85}$ que conduce al aislamiento al rechazar como aliado al partido comunista y reconocer al MIR como único interlocutor válido. Asimismo, Altamirano reflexiona sobre las causas de la derrota del proyecto de la UP y las ordena en tres causas fundamentales: primero, una equivocada política hacia las fuerzas armadas; segundo, una incapacidad desde el PSCh de "responder al desafío planteado por la ruptura del bloque ideológico de dominación", lo que permitió el surgimiento de "desviaciones izquierdistas que, entre otros errores, nos llevó a subestimar la enorme gravitación de las clases medias en la sociedad chilena" y finalmente el error de sobrevalorar las singularidades nacionales, "llegando a considerar que dichas singularidades nos eximían de reconocer las leyes generales del marxismo en materias tan básicas como la del Estado y el poder". ${ }^{86}$

A pesar de las diferencias que el "Documento de marzo" subrayó, en esta primera etapa, existía cierto consenso general, al menos en los discursos públicos, tanto desde la Dirección Exterior como las agrupaciones que disputaban el poder al interior de Chile, de la necesidad de mantener la unidad en el partido, la inevitabilidad de la resistencia armada en la

82 A pesar de que la posición defendida por la CNR perdió peso al interior del partido y su líder (Pedro Vuskovic) fue expulsado, muchos miembros del partido al interior siguieron prefiriendo entablar vínculos con el MIR. Especialmente frente a la dirección que podía tomar el movimiento popular una vez que la democracia cristiana se movió a la oposición y la Iglesia católica tomó activamente una posición contraria al régimen. No obstante, el MIR en 1974 sufrió duros golpes por parte del régimen y la posibilidad de formar un polo revolucionario se debilitó frente a una opción más reformista sostenida por el comunismo. Pollack y Rosenkranz, op. cit., p. 194.

${ }^{83}$ CNR, "Carta al Secretario General del PS, Carlos Altamirano", Chile-América, Roma, No. 31-32, mayo-junio, 1977, p.119.

84 Carlos Altamirano, "Mensaje a los socialistas de Chile", junio de 1977. Documento extraído del sitio web http.www.socialismo-chileno.org, visitado el 15 de septiembre de 2015.

85 Altamirano, Ibid., p. 50-51.

86 Altamirano, Ibid., p. 13. 
lucha contra la dictadura, la adscripción al marxismo-leninismo y la concepción leninista de la toma del poder a través de la revolución. ${ }^{87}$

\section{División del PSCh}

Hacia finales de la década del 1970, las diferencias entre liderazgos, apreciaciones en torno el régimen militar, alianzas y proyecciones se fueron acentuando. Además, el contexto del exilio eventualmente obligó al socialismo chileno a posicionarse frente a los temas en debate. Por un lado, las consecuencias políticas de la Revolución sandinista en Nicaragua ${ }^{88}$ actuaron como confirmación doctrinaria para los postulados del giro estratégico del comunismo, el que, para fines de la década de 1970 en sintonía con el comunismo soviético, incluía la estrategia armada para enfrentar la dictadura. ${ }^{89}$ Por otro lado, las propuestas del Eurocomunismo en Europa occidental adquirieron fuerza, especialmente luego del golpe en Chile en países como Italia, Francia y España, polarizando el comunismo internacional. Este reordenamiento ideológico en la izquierda mundial caló fuertemente en las discusiones teóricas que la izquierda chilena desarrollaba. Especialmente en aquella situada en el exilio, lo que determinó profundamente el devenir del socialismo.

En vista de lo anterior, dentro del socialismo se perfiló un sector cercano a la Unión Soviética y atento a los giros que se estaban desarrollando en el comunismo internacional con respecto a la vía armada. Clodomiro Almeyda, durante el pleno de Argel en 1978, se perfiló como la figura principal de este sector dentro del socialismo.

En paralelo, el acercamiento a la internacional socialista y a los contactos en Europa occidental, principalmente debido a las redes de solidaridad organizadas para denunciar el régimen militar, expuso a algunos socialistas en el exilio al debate intelectual que la experiencia chilena, la UP, el golpe militar, y la solidaridad internacional, habían generado al oeste de la cortina. Además de la influencia del Eurocomunismo, Ricardo Núñez también destaca la influencia de los partidos socialistas y socialdemócratas de Occidente.

A pesar de la existencia de dichos sectores, durante el pleno de Argel desarrollado en 1978, se concretizó la conformación de una Dirección Única, conscientes de la necesidad de mantener un sentido de unidad ante la adversidad. Argel significó un momento de inflexión para el socialismo. Ricardo Núñez, quien estuvo presente en el pleno, sostuvo que en ese momento aún no había claridad en las estrategias para derrotar a la dictadura y al menos en apariencias aún no se debatían abiertamente las ya mencionadas diferencias teóricas que estaban surgiendo al interior del socialismo. ${ }^{90}$

Junto con el perfilamiento, aún no declarado por entonces, de diferencias de fondo al interior del socialismo, alrededor del año 1978, así como existían grupos que apoyaban la idea de un polo revolucionario, emergieron también varios grupos socialistas tanto al interior como al exterior de Chile de tendencia más moderada. Pollack y Rosenkranz, los enumeran de la siguiente manera: En 1978 se lanzó el grupo Movimiento de Acción Socialista (MAS) que se desmarcaban del leninismo y se denominaban a sí mismos como 'democráticos socialistas'; la

\footnotetext{
${ }^{87}$ Kenneth Roberts, Deepening Democracy? The modern Left and Social Movements in Chile and Peru, Stanford, Stanford University Press, 1998, p. 103

88 Ver artículo de Cristián Pérez, "Compañeros, a las armas: combatientes chilenos en Centroamérica (1979-1989)", Estudios Públicos, No 129, 2013, pp-141-164.

89 Ver: Riquelme, op. cit.

90 Ver: Fernández, Góngora y Arancibia, op. cit.
} 
Tendencia Humanista Socialista, cercanos a Aniceto Rodríguez; la Comisión para el Consenso se identificaban como marxistas, pero no leninistas y el Movimiento Recuperacionista, formado por Eduardo Long, de ideas social demócratas. Todos estos grupos emitieron una declaración llamada: "Declaración de Unidad Socialista" defendiendo la unidad del partido, pero criticando el sectarismo del liderazgo. Para 1980, el ala moderada se había ampliado para incluir al grupo intelectual de los "Suizos"; la Iniciativa Regional Europa y el grupo: la Unión Socialista Popular de Ampuero, quién se había separado del partido en 1967. Todos estos grupos concordaban en que la derrota del régimen militar sólo podía establecerse bajo negociaciones con la DC, la derecha democrática y los sectores democráticos de las fuerzas armadas, excluyendo al PCCh y a la izquierda extrema y dejando de lado los objetivos socialistas por un tiempo indefinido. ${ }^{91}$

En sintonía con estas tendencias más moderadas, pero desde un proceso distinto, Mireya Dávila, ${ }^{92}$ reconoce en el informe final del pleno de Argel, firmado por Altamirano, el perfilamiento de un proceso de reflexión distinto al desarrollado por el sector cercano a Almeyda. Altamirano retoma el concepto de democracia como un elemento importante del proyecto socialista, criticando a su vez el concepto de democracia abordado durante la UP. Asimismo, se presenta una cierta distancia respecto del pensamiento del marxismo-leninismo ya que plantea que la fundamentación teórica del partido debe ser una "asimilación activa y creadora de las premisas filosóficas y científicas del marxismo y del leninismo, y no de un mero intento de erudición o repetición". ${ }^{93}$ En este sentido, Altamirano, contradiciendo los mensajes anteriores, en el Pleno de 1978 sostiene:

La más grande distorsión que hemos podido observar en torno a este tema reside en la tendencia a aceptar acríticamente y en forma dogmática una concepción presuntamente "leninista " de Partido, que se supone ha de constituir la generalización científica de la experiencia universal de conducción de la clase obrera y el campesinado, en su combate anticolonial y anticapitalista. ${ }^{94}$

Altamirano además promueve una alianza con la DC para enfrentar a la dictadura, alejándose del "Documento de marzo". Finalmente, aboga por la unidad del Partido, la que constituye "exigencias de la lucha contra la dictadura y del éxito del Movimiento de Solidaridad Internacional". 95 En el informe, Altamirano además destaca el aporte de partidos socialistas occidentales, sosteniendo las relaciones internacionales del PSCh previas al golpe, "influyó, indudablemente, [en] un enfoque provinciano y esquemático de la realidad internacional, lo que nos llevó - entre otras cosas - a subestimar cualquier tipo de relación con los partidos socialistas y social-demócratas europeos". ${ }^{96} \mathrm{Al}$ contacto con partidos socialistas de occidentes, se sumó el impacto que significó para un grupo de socialistas, la experiencia de vida en el exilio en países capitalistas que tenían fuertes políticas sociales en marcos democráticos.

${ }_{91}$ Pollack y Rosenkranz, op. cit., p. 192.

92 Mireya Dávila, Historia de las ideas de la renovación socialista 1974-1989. Tesis de Licenciatura en Historia, Santiago de Chile Pontificia Universidad Católica de Chile, 1994.

${ }^{93}$ Carlos Altamirano, "Informe del Secretario General Camarada Carlos Altamirano al Pleno extraordinario del Comité Central del Partido Socialista”. Obtenido de Partido Socialista de Chile: www.socialismo-chileno.org/1978 en 2015, 1978, s/p.

${ }^{94}$ Idem.

${ }^{95} \mathrm{I} d e m$.

${ }^{96}$ Idem. 
Las diferencias entre los sectores liderados por Almeyda y Altamirano aumentaron o más bien se evidenciaron luego del Pleno de Argel, impulsando una serie de medidas re organizativas, entre ellas, el reemplazo de Altamirano como Secretario General por Almeyda, medida ignorada por Altamirano. Esto derivó en su expulsión del partido en 1979. Frente a esto, Altamirano decidió presentar una Dirección alternativa desde París, gestándose así la división. En un principio, gran parte de los socialistas en el exilio se agruparon en torno a Carlos Altamirano, mientras que, al interior de Chile, se mantuvieron bajo el liderazgo de Almeyda. Sin embargo, señalan Pollack y Rosenkranz, ${ }^{97}$ la confusión ideológica inicial luego de la división devino en una serie de fragmentaciones que implicaron fuertes y profundos procesos de reflexión teórica en torno al socialismo.

Altamirano desde su nueva posición en Europa Occidental, buscó apelar a la unidad convocando a todos los grupos que se habían enfrentado a la Dirección Interior. ${ }^{98}$ Éstos incluían desde grupos moderados como los Recuperacionistas a miembros de la CNR. Con este fin, se organizaron diversos congresos para sentar las bases de la unidad. Ejemplo de lo anterior, es la reunión impulsada por el sector Altamirano y ex integrantes de la CNR en Caracas el año 1981, desde donde emana el documento “Unidad Socialista para vencer". En una carta firmada por Guillermo Cubillos y Aniceto Rodríguez, dirigida al Secretario General de la Internacional Socialista, Bernt Carlsson, en donde se adjunta dicho documento, los dirigentes socialistas explican el desarrollo de diversos congresos orientados a recuperar la unidad del partido luego de haber roto "con el ala estalinista de Berlín". En dicha carta, aclaraban su adhesión al socialismo científico "que excluyó al marco rígido del "marxismoleninismo" que había verticalizado totalitariamente la vida interna del partido". En el documento adjunto, se establecían ciertas condiciones para el diálogo hacia la unificación que parten con la necesidad de "análisis críticos y autocríticos, así como una confrontación constructiva de nuestras identidades y discrepancias". Además, se señalaba la necesidad de "definir el proyecto histórico estratégico por el cual luchan los socialistas chilenos". Para cumplir la voluntad unitaria de quienes suscriben este documento (entre los que se encuentran representantes de la DC, el PC, IC, PR, MIR, MAPU, MAPU OC, e independientes de izquierda) se acordó formar un comité de unidad socialista, coordinar el trabajo socialista en el exilio y crear una comisión organizadora de actos conmemorativos del 48 aniversario del PSCh. ${ }^{99}$

Dicha reunión se enmarcó con las iniciativas desarrolladas principalmente por socialistas del sector Altamirano, representantes de los MAPU y la IC por proponer una nueva fórmula de organización política que superase los errores cometidos por el conglomerado de la UP. Las reflexiones teóricas que estos sectores venían desarrollando, alimentados por los debates presentes en Europa occidental, tuvieron como ejes principales dos puntos centrales que definieron el proyecto socialista por las siguientes décadas: por un lado, una revalorización de la democracia como marco regulatorio para el juego político, y por otro, un alejamiento del marxismo leninismo como dogma. Como resultado de estas reflexiones, se cuestionó el tipo de organización política que se sostenía en la izquierda. Fue así como se instaló la idea de crear un

\footnotetext{
${ }^{97}$ Pollack y Rosenkranz, op. cit.

${ }^{98}$ El sector Altamirano convoca el XIV Congreso acentuando la división del socialismo. A partir de entonces, su sector será conocido como PSCh XIV Congreso.

${ }^{99}$ Guillermo Cubillos y Aniceto Rodríguez, carta enviada a Bernt Carsson, 7 de septiembre de 1981, Socialist International, Comisco y SILO. Box Número 1066. Archivo de la Internacional Socialista. Instituto Internacional de Historia Social. Amsterdam.
} 
nuevo proyecto político de izquierda que suponía nuevas alianzas y estructuras orgánicas. La reconsideración de la democracia y, por ende, la necesidad de buscar mayorías para la introducción de proyectos políticos ponía a la idea de consenso en el centro del debate sobre las maneras de entender el proyecto socialista. En este sentido la idea de la Convergencia Socialista surgió "como el más serio intento de concretizar políticamente la existencia de una corriente cuya acción se ha circunscrito hasta ahora principalmente al terreno de las ideas". ${ }^{100}$ La Convergencia por ende comenzó como una instancia de encuentro entre personas de distintas corrientes socialistas de todos los sectores, miembros de partidos de distinto origen, intelectuales sin militancia, etc., con el objeto de insertar en una estructura organizativa las ideas de la Renovación.

No obstante, pronto las diferencias ideológicas al interior del socialismo en torno a las alianzas con partidos de clase media, la relación con el comunismo soviético, el tipo de partido que se buscaba construir y las estrategias inmediatas para derribar el régimen militar, se evidenciaron. El polo de izquierda se sintió cada vez más incómodo con la cercanía del sector Altamirano con el bloque Convergencia, el que era visto "como un potpurrí de partidos caracterizados por blandura política y ánimos de congraciarse con partidos burgueses". ${ }^{101} \mathrm{De}$ este modo, dicha facción (conocida como Álzate Chile), se escindió de la iniciativa de Altamirano. Sin esta facción de izquierda, la facción de Altamirano estuvo compuesta en su mayoría con tendencias orientadas al espíritu representado por el grupo Convergencia. En una carta firmada por Carlos Altamirano, Aniceto Rodríguez y Roberto Ampuero en octubre del año 1982, se estableció que el partido no se sometería nunca más a la voluntad del PCCh a la vez que se revalorizaba la alianza con fuerzas socialistas de tendencia cristiana y las fuerzas democráticas progresistas de centro. En referencia al proyecto de Convergencia en la carta declararon: "se trata de construir un consenso nacional para el cambio, en el que confluyan las constantes históricas del socialismo chileno (...) y los valores solidarios y humanistas del movimiento cristiano". ${ }^{102}$

De trascendental importancia en torno a la construcción del movimiento de Convergencia, se situaron las reuniones realizadas en Ariccia, Italia, pues en ellas fue la primera vez, en donde representantes del socialismo tradicional y representantes de la vertiente cristiana del socialismo, se encontraban en torno a las ideas de la Renovación. Tan importantes como las reuniones de Ariccia, fueron los encuentros organizados en Chantilly, Francia los años 1982 y 1983. Encuentros que también fueron decisivos para la aglutinación del proceso de convergencia. ${ }^{103}$ La primera reunión tuvo como título "Chile-80: Movimientos, Escenarios y Proyectos" y se discutieron diversos temas relacionados con la situación chilena, tales como: sindicalismo, situación económica, situación de la mujer, etc. Entre los temas planteados y de mayor importancia en términos ideológicos fue el consenso que se generó en torno a la necesidad de abandonar el esquema marxista-leninista como marco teórico para el socialismo en general. ${ }^{104}$ La selección temática del debate ya daba cuenta del tenor de la discusión y la

\footnotetext{
${ }^{100}$ Carlos Ominami, "De la ideología a la política”, Revista Chile América, No. 78-79, pp.15-19, 1982, p.15.

101 Pollack y Rosenkranz, op. cit., p.198.

102 Robert Ampuero, Carlos Altamirano y Aniceto Rodríguez, "Declaración de los ex secretarios generales del Partido Socialista de Chile". En Ricardo Nuñez (Ed.), Socialismo. Diez años de Renovación. 1979-1989 De la Convergencia a la Unidad Socialista, Santiago de Chile, Ediciones del Ornitorrinco, 1991, pp.107-115, p. 113.

103 Dávila, op. cit.

${ }^{104}$ Durante el encuentro se trataron 4 temas generales que convocaban a diversos intelectuales tanto del exilio como de Chile. Los temas de discusión fueron: "Problemas del marxismo, el Socialismo y la Democracia"; "Presencia y composición de las
} 
dirección que la corriente de la Renovación estaba tomando en términos políticos. El segundo encuentro, tuvo como título "Los desafíos de la redemocratización" y continuando con las temáticas del primer congreso, se debatió sobre la necesidad de desacralizar el marxismo y se buscó confrontarlo, en tanto matriz teórica, a otras realidades conceptuales como la democracia y el socialismo. ${ }^{105}$

Desde el PCCh y la vertiente Almeydista del PSCh, las ideas de Renovación y su articulación a través de la Convergencia evidenciaba no solo "tendencias de derecha que se manifiestan en una crítica negativa -de obsolencia- del marxismo, y de conceptos como el lucha de clases y carácter de clase de un Estado", "sino que además un despropósito para la organización de la lucha en contra del régimen militar. ${ }^{107}$ La constatación de estas reacciones permite comprender la diversidad de caminos tomados entre la izquierda chilena, especialmente aquella del exilio, frente al desafío (tanto intelectual como político) impuesto por el golpe militar. Orlando Millas, uno de los líderes más importantes del PCCh, sostuvo sobre el proceso de Renovación en general y las reuniones de Chantilly en particular:

Allí se quiso formular a la manera de las sentencias judiciales condenaciones al método marxista. Y en las intervenciones se propició por algunas personas llamados a pasar de la primera renovación -como se calificó al antimarxismo- a una segunda renovación inspirada en el neoconservantismo monetarista de Friedman (...) Se levantó tribuna pretendiendo declarar "inviable" el gobierno de Allende. Se manifestó simpatía por las "modernizaciones" pinochetistas. ${ }^{108}$

Orlando Millas llegó a catalogar la reunión de Chantilly como: "la manifestación de un anticomunismo morboso. En resumen, se dijeron disparates demasiado reaccionarios" ${ }^{109}$ Además, desde el sector Almeyda, se sostuvo que la Convergencia: "altera el contenido esencialmente clasista y revolucionario de nuestro proyecto socialista", en donde se debe plantear la rearticulación de la unidad de la izquierda en un "fortalecimiento de la alianza PS-

fuerzas sociales en conflicto"; "Evolución político-cultural del régimen militar y escenarios posibles de una transición a la democracia"; "Sobre los contenidos de una propuesta alternativa" Actas del encuentro de Chantilly I. "Chile-80 Movimientos, Escenarios y Proyectos", Revista Chile América, Roma, No. 82-83, 1982.

$105 \mathrm{Al}$ igual que en el encuentro anterior, la discusión se realizó en torno a 4 grandes temas: "La dimensión cultural de la redemocratización"; "Fuerzas armadas y Relaciones internacionales"; "Movilización Popular y fuerzas sociales"; "Marxismo, Socialismo y Redemocratización". Actas del encuentro de Chantilly II, "Los Desafíos de la Democratización", En Ricardo Núñez (Ed.), Socialismo: 10 años de Renovación. 1979-1989 de la Convergencia a la Unidad Socialista, Santiago de Chile, Ediciones del Ornitorrinco. 1991, pp.138-154.

106 Partido Socialista de Chile, "Crisis de la izquierda según el pleno clandestino de los socialistas de Chile", Revista Chile América, Roma, No.78-79, 1982, pp. 93-94, p. 93.

107 En torno a un llamado de unidad amplia del mundo de izquierda en contra del régimen de Pinochet y a propósito de iniciativas como Convergencia, Luis Corvalán, líder del PCCh dice: "Los comunistas no rehuimos la discusión sobre ningún tema, pero preferimos discutir en medio del combate y ante todo para combatir mejor" Luis Corvalán, "La unidad de toda la izquierda chilena", Revista Chile América, Roma, No.78-79, 1982, pp.88-90, p. 90.

108 Orlando Millas, "No hemos dicho que en Chile este a la orden del día la lucha armada", Revista Chile América, Roma, No. 84-85, 1983, pp.51-54, p. 53. Las críticas de O. Millas sobre la valoración del manejo económico del régimen militar, se refieren a las declaraciones por parte de algunos importantes representantes de la corriente renovacionista, en torno al crecimiento económico que el modelo adoptado por el régimen militar, había alcanzado. Por ejemplo, Carlos Ominami sostuvo: "La derrota de la Unidad Popular nos llevó a constatar que era imposible conducir una política económica autárquica y proteccionista. La experiencia militar puso en evidencia que el crecimiento económico era factible solamente al abrirse a los mercados internacionales. Para nosotros, uno de los cambios fue constatar que el mercado no es más reaccionario que el Estado [...] en cierto sentido, el mercado trae consigo cierta impersonalidad mucho más deseable que la administración económica del Estado". Citado en Javier Santiso, "La democracia como horizonte de espera y campos de experiencia: el ejemplo chileno", Revista de Ciencia Política, No. 2, Vol. XXI, 2001, pp.69-100, p. 86.

${ }^{109}$ Millas, op. cit., p. 53. 
PC". ${ }^{110}$ Consultado sobre la iniciativa de la Convergencia, Clodomiro Almeyda, en línea con lo señalado por el PCCh, señalaba que el afán de dividir a la izquierda presente en la Convergencia contribuyía a los objetivos de los adversarios del mundo popular. ${ }^{111}$

Dentro de la facción liderada por Almeyda, también existieron disputas internas. La adhesión, en un primer momento, del PSCh Almeyda al Comité de Enlace, que buscaba elaborar fórmulas para la unificación socialista, respondió a una petición de quienes consideraban que la división del socialismo respondía más bien a diferencias personales, y que la necesidad de un partido socialista unificado estaba por sobre diferencias ideológicas. Sin embargo, una gran porción del liderazgo, estaba en desacuerdo con esta adhesión. Desacuerdo que aumentó cuando el Comité de Enlace entabló negociaciones con Tomás Reyes de la DC. Así en un pleno realizado por el Comité Central del PSCh Almeyda en 1982, decidieron retirarse del Comité de Enlace, actuando en oposición a la fracción (representada por Julio Stuardo y Carlos Briones) que buscaba apuntar a la unificación del partido. La Fracción Stuardo-Briones, criticaba la postura del ala izquierda del PSCh Almeyda que defendía una resistencia armada, debido que la seriedad de la crisis que la dictadura ocasionó requería la unidad de una gran oposición democrática de las fuerzas socialistas para su derrota. Dicha disputa, ocasionó una nueva fragmentación del socialismo. ${ }^{112}$

Vale destacar en este punto, frente a este tumultuoso período de escisiones y reconfiguraciones, que la deconstrucción de programa de la izquierda chilena tanto al interior del país como en el exilio, a la luz de la crisis de representación del fracaso del proyecto político de la izquierda, como advierte Valderrama, en su origen no contenía ni línea ni estrategia política específica "sino un cambio ideológico y, más precisamente, cultural, en cuyo interior podían darse muy diversas líneas o estrategias políticas". ${ }^{113}$ Esto explica la presencia de múltiples formas de reconstrucción de la izquierda chilena post golpe de estado y los constantes fraccionamientos que definieron la época.

Para el año 1983, la trayectoria del socialismo chileno componía la configuración de dos polos entre la oposición al régimen militar. Por un lado, la DC, grupos de derecha no pinochetista y algunos representantes del PR y PS, firmaron el Manifiesto democrático, el que luego se transformó en el grupo llamado Alianza Democrática, coalición que reunió a la DC, el Partido Liberal, el PR y el PS del sector de la Renovación que para entonces llevaba el apellido Núñez. Dicha coalición inició diálogos con el ministro del interior del régimen; Sergio Onofre, en contexto de una serie medidas de aperturas que el régimen se había visto en la obligación de instaurar a propósito de las presiones internacionales y el surgimiento de una movilización interna producto de la crisis económica. Sin embargo, Pinochet desechó estos intercambios en septiembre de $1983 .{ }^{114}$ En paralelo, y a modo de reagrupar las corrientes socialistas chilenas, el mismo mes de septiembre, se crea el Bloque Socialista, integrado por iniciativas como el Secretariado por la Convergencia (PSCh XIV Congreso, MAPU OC, MAPU e IC), el Grupo por la Convergencia (intelectuales) y el Grupo por la Convergencia Universitaria. ${ }^{115}$ En

\footnotetext{
110 Partido Socialista de Chile, op. cit., p. 94.

111 Clodomiro Almeyda, "El legado de Allende es su llamamiento persistente a la unidad", Revista Chile América, Roma, No. 8283, 1982, pp. 37-40.

112 Pollack y Rosenkranz, op. cit., p. 201-202.

113 Valderrama, op. cit., p. 24.

114 Ver: Víctor Muñoz, "El Partido Socialista de Chile y la presente cultura de facciones. Un enfoque histórico generacional (1973 - 2015)", Revista Iqquierdas, Santiago de Chile, No.26, 2016.

115 Ver: Rojas, op.cit.
} 
definitiva, a través de esta alianza política, lo que se buscó era acercar a los socialistas históricos con los socialistas de origen cristiano pertenecientes a los MAPU y la IC, proyectando la posibilidad de formar alianzas entre el socialismo y la DC, alejándose del comunismo. No obstante, este marco tampoco proliferó en el tiempo, debido tanto a la multiplicidad de alianzas y a las indefiniciones político-estratégicas de quienes la componían.

Por otro lado, el mismo año 1983, el PCCh, el MIR y el PSCh Almeyda elaboraron su propio frente: el Movimiento Popular Democrático (MDP). La diferencia entre ambas asociaciones radicaba en las alianzas debido a la incompatibilidad de la DC con el PCCh y la estrategia para derribar la dictadura. En dicha agrupación se plasmaba la política del PS Almeyda para enfrentar la dictadura conocida como "lucha de masas rupturista con perspectiva insurreccional" la que incluía la validez de "todas las formas de lucha que contribuyan a consolidar y potenciar el movimiento de masas", que había sido confirmada en el congreso XXIV del PSCh Almeyda del año 1985. Postura que coincidía con el ya mencionado giro comunista. ${ }^{116}$ Dicha postura fue la causante de la escisión del grupo Stuardo-Briones ya mencionado, el que se incorpora al PSCh Núñez, reforzando la predominancia de la versión renovada del socialismo.

Vale destacar, que las mencionadas posiciones representan a las más predominantes, pues como señala Muñoz, durante los años 1980, llegan a existir cerca de una veintena de agrupaciones socialistas orgánicas. En la misma línea, Rojas sostiene que:

la coyuntura de la época estuvo invadida de propuestas convergentes, aliancistas e intentos de reunificaciones. Lo anterior convirtió a la arena política chilena en un excéntrico panorama de inclusiones y exclusiones, que en la práctica solo hizo más estéril el proceso de oposición al régimen". 117

Hacia 1987, empezaron las primeras aspiraciones unificadoras en el socialismo. Para entonces, diversos grupos de los MAPU, y representantes de las Convergencias, habían adherido al PSCh de la vertiente renovada. El PSCh XXIV Congreso, ahora liderado por Ricardo Núñez, había conseguido exitosamente, la unión de diversas facciones del socialismo. Por su parte, el sector Almeydista, que venía de vivir fragmentaciones, ${ }^{118}$ flexibilizó la disposición de socialistas almeydistas a pensar en la unidad. Esta disposición se consolidó con el fracaso de la vía insurreccional del PCCh el año 1986, fracaso articulado a través de dos hitos fundamentales: el descubrimiento por parte del régimen militar de la operación Carrizal que tuvo como objetivo dotar de armas al PCCh y el fallido intento de asesinato a Pinochet por parte del Frente Patriótico Manuel Rodríguez. Ambos episodios marcaron "el ocaso de la política de rebelión popular de masas del PC chileno". ${ }^{119}$ Este ocaso del PCCh, mencionado por Pérez, significó el quiebre de la relación entre PS Almeyda y el PCCh, al ver reducida, éste

116 Muñoz, op. cit., p. 228-229.

117 Rojas, op.cit. p. 327.

118 Mauricio Rojas enumera tres tendencias presentes en el Almeydismo: la primera liderada por Clodomiro Almeyda, adhirieron al marxismo-leninismo y fueron cercanos al PCCh, aunque mantuvieron una postura ambigua frente a la validez de la lucha insurreccional; la segunda fueron los "Terceristas", ubicados al interior de Chile, promovieron la fórmula de Ruptura pactada y fueron proclives a un acuerdo unitario con el resto de las fuerzas socialistas renovadas; y por último, la corriente liderada por "Los Comandantes", que en contra de la ruptura pactada con la dictadura, promovieron el fortalecimiento del movimiento popular para radicalizar el enfrentamiento. Si bien adherían al marxismo-leninismo, marcaron sus distancias con el PCCh. Luego del XIV Congreso, esta tendencia se escindió del Almeydismo y desde el exterior (Bruselas) formaron la facción PS-Dirección Colectiva. Rojas, Ibid., p. 372-373.

119 Pérez, op.cit, p. 160. 
último, su posibilidad real de incidencia en la política nacional, agregándose un capítulo más al vínculo relacional entre socialismo y comunismo identificado en un apartado anterior. Sumado a lo anterior, y luego del paro de julio del año 1986, se impuso la lógica dentro de la oposición política del fracaso de la movilización política como estrategia para derribar el régimen y se impuso "una visión pragmática de la negociación con el régimen dentro de su institucionalidad jurídica". ${ }^{120}$

Finalmente, el perfil del socialismo almeydistas se orientó hacia el socialismo renovado, cuando en enero de 1988 llama públicamente a votar NO en el plebiscito. Con este gesto, se alejó de la vía insurreccional para derrotar a la dictadura al mismo tiempo que se validaba la estrategia del socialismo renovado. En este contexto, la corriente Tercerista asumió el control manifestando su adherencia a la renovación y la unidad del socialismo. El 29 de diciembre de 1989 se oficializó la reunificación del socialismo en donde Jorge Arrate (líder del socialismo renovado luego de Ricardo Núñez) asumió como secretario general y Clodomiro Almeyda como presidente. En términos generales, como sostiene Mireya Dávila "El Partido Socialista asumió la renovación socialista como la base ideológica de sustentación partidaria". ${ }^{121}$ Según Heraldo Muñoz, una explicación para que finalmente se haya impuesto la vertiente renovada en el tronco central del PSCh, fue que se lograron imponer las ideas de un nuevo socialismo necesario para las nuevas condiciones sociales en Chile. "por su capacidad de articular un nuevo pensamiento socialista, una nueva imagen socialista -más pragmática, más realista, más en sintonía con el sentimiento popular (...) Creo que esa presencia intelectual, esa capacidad de visión, nos permitió terminar siendo la principal fuerza". ${ }^{122}$

A la lectura intelectual que hace Muñoz, habría que agregar el profundo trauma, que los rebrotes de violencia hacían evidentes entre los movimientos sociales en el país. Trauma que se tradujo en una desarticulación de los movimientos sociales, el consecuente fracaso de la política implementada por el PCCh y la decisión, por ende, de apoyar una política pacifica de transición hacia la democracia, representada por las fuerzas de la renovación. ${ }^{123}$

El partido ya unificado, no terminó con la presencia de corrientes diversas, pero si asumió una posición estratégica de unirse pragmáticamente en torno al programa y a su rol en la transición hacia la democracia y al interior de la Concertación de Partidos por la Democracia.

\section{Conclusiones}

Las reconfiguraciones políticas que se desarrollaron en la izquierda chilena luego del golpe de estado fueron múltiples. Luego de una crisis de la magnitud del golpe de estado en Chile, los ideólogos de los distintos partidos y movimientos políticos debieron recurrir a nuevos planteamientos para hacer frente a una realidad drásticamente distinta. La

120 Viviana Bravo, "Neoliberalismo, protesta popular y transición en Chile, 1973-1989”, Política y Cultura, No 37, 2012, pp. 85112, p. 109.

121 Dávila, op.cit., p. 92.

122 Citado en Jeffrey Puryear, Thinking politics: intellectuals and democracy in Chile, 1973-1988, Baltimore, Johns Hopkins University Press. 1994, p.64.

123 Sobre relación entre trauma, transformaciones del proyecto neoliberal sobre la sociedad chilena y la corriente de la renovación tras el paradigma de la gobernabilidad que aplicó la Concertación durante la transición ver: Camila Jara, Trayectorias de (des)movilización de la sociedad civil chilena. Post-trauma, gobernabilidad y neoliberalismo en la restauración democrática (1990-2010), Tesis doctoral, Universidad de Leiden, Leiden. 2016. 
reconfiguración política se desarrollaba en ambientes tan diversos y hostiles como el exilio o bajo la persecución política al interior de Chile de un régimen que duró 17 años. Estas circunstancias significaron que la izquierda chilena en su conjunto tuvo que cuestionar y transformar sus postulados políticos para poder ser parte del proceso en contra de la dictadura instalada en Chile. No obstante, como se pudo observar, lejos de tratarse de un proceso homogéneo, los cuestionamientos y reconstrucciones políticas se desarrollaron de manera distinta entre las agrupaciones políticas. Para el caso del socialismo chileno, las divergencias se alojaron en el seno mismo del partido, luego de una severa crisis que fragmentó y dividió a sus representantes. Lo anterior, además de las circunstancias especiales de una dictadura militar, se debió a una naturaleza originaria heterogénea, la influencia del contexto político del exilio, las circunstancias al interior del país, y el rol clave jugado por los líderes del partido. Al igual que en su fundación, en donde convivieron diversas tendencias, el PSCh en su reunificación, logró armonizar sus tendencias internas reuniéndose en torno a un programa específico, sin ahondar en principios ideológicos más profundos. Solo una mirada pragmática de lo acordado en el programa político, (durante su fundación y durante la transición democrática) y una decisión estratégica para ser un actor relevante en la política, es lo que ha logrado mantener unido a un partido que alberga corrientes tan diversas.

\section{Fuentes impresas}

Almeyda, Clodomiro, "El legado de Allende es su llamamiento persistente a la unidad", Revista Chile América, Roma, No. 82-83, 1982

Almeyda, Clodomiro. "Entrevista a Clodomiro Almeyda. El legado de Allende es su llamamiento persistente a la unidad", Revista Chile América, No. 82-83, Roma, Octubre-NoviembreDiciembre 1982.

Álvarez, Rolando, Desde las sombras. Una historia de la clandestinidad comunista (1973-1980). Tesis para optar al grado de Magíster, Santiago de Chile, Universidad de Santiago, 2001.

Álvarez, Rolando, La tarea de las tareas: luchar, unir, vencer. Tradición y renovación en el Partido Comunista de Chile (1965-1990), Santiago de Chile, Tesis Doctoral, Universidad de Chile, 2007.

Ampuero, Robert, Carlos Altamirano y Aniceto Rodríguez, "Declaración de los ex secretarios generales del Partido Socialista de Chile". En Ricardo Nuñez (Ed.), Socialismo. Diez años de Renovación. 1979-1989 De la Convergencia a la Unidad Socialista, Santiago de Chile, Ediciones del Ornitorrinco, 1991.

Arrate, Jorge, El socialismo chileno: rescate y renovación, Barcelona, Ediciones del Instituto para un Nuevo Chile, 1983.

Arrate, Jorge y Eduardo Rojas, Memoria De La Izquierda Chilena, Tomo1, Santiago de Chile, Ediciones B Chile S.A, 2003.

Arrate, Jorge, Pasajeros en tránsito, Santiago de Chile, Catalonia, 2007.

Barnard, Andrew, "Chile", En Leslie Bethell y Ian Roxborough (Edits.), Latin America between the Second World W ar and the Cold War 1944-1948 (66-91), Cambridge, Cambridge University Press, 1992.

Bravo, Viviana, "Neoliberalismo, protesta popular y transición en Chile, 1973-1989", Politica y Cultura, No 37, 2012, pp. 85-112.

Bermeo, Nancy, "Democracy and the Lessons of Dictatorship", Comparative Politics, No. 3, Vol. 24, Nueva York, 1992, pp. 273-291.

Casals, Marcelo, El alba de una revolución. La izquierda y el proceso de construcción estratégica de la "vía chilena al socialismo" 1956 - 1970, Santiago de Chile, LOM Ediciones, 2009. 
CNR, "Carta al Secretario General del PS, Carlos Altamirano", Chile-América, Roma, No., 3132, mayo-junio, 1977.

Corkill, David, "The Chilean Socialist Party and The Popular Front 1933-41", Journal of Contemporary History, No. 2/3, Vol. 11, 1976, p.261-273.

Dávila, Mireya, Historia de las ideas de la renovación socialista 1974-1989. Tesis de Licenciatura en Historia, Santiago de Chile Pontificia Universidad Católica de Chile, 1994.

Devés, Eduardo y Carlos Día (Ed.), El Pensamiento socialista en Chile: antología, 1893-1933, Santiago de Chile, América Latina Libros, 1987.

Drake, Paul, Socialism and Populism in Chile, 1932-1952, Champaign, University of Illinois Press, 1978.

Faúndez, Julio, Marxism and Democracy in Chile. From 1932 to the fall of Allende, New Haven, Yale University Press, 1988.

Fermandois, Joaquín, La Revolución Inconclusa. La izquierda chilena y el gobierno de la Unidad Popular. Santiago de Chile, Centro de Estudios Públicos, 2013.

Fernández, Joaquín, Álvaro Góngora y Patricia Arancibia (Eds.), Ricardo Núnę: Trayectoria de un socialista de nuestros tiempos, Santiago de Chile, Ediciones Universidad Finis Terrae. 2013.

Garretón, Manuel A, Las ideas de la renovación socialista. Sintesis y Balance. Material de Trabajo, Santiago, Flacso, 1987.

Garretón, Manuel A. y Malva Espinosa, "Chile: Political Learning and the Reconstruction of Democracy", En Jennifer McCoy (Ed.), Political Learning and Redemocratization in Latin America: Do Politicians Learn from Political Crises?, Florida, North-South Center Press at University of Miami, 2000.

Gómez, María Soledad, "Factores nacionales e internacionales de la política interna del Partido Comunista de Chile (1922-1952)", En Augusto Varas, Alfredo Riquelme y Marcelo Casals (Edits.), El Partido Comunista en Chile. Una historia presente, Santiago de Chile, Editorial Catalonia. 2010, p. 75-120.

Góngora, Mario, Ensayo histórico sobre la noción de Estado en Chile en los siglos XIX y XX, Santiago de Chile, Editorial Universitaria, 1986.

Halperin, Ernst, Nationalism and Communism in Chile, Cambridge, The M.I.T Press, 1965.

Huneeus, Carlos, La guerra fría chilena. Gabriel González. Videla y la Ley Maldita. Santiago de Chile, Random House Mondadori, 2009.

Jara, Camila, Trayectorias de (des)movilización de la sociedad civil chilena. Post-trauma, gobernabilidad y neoliberalismo en la restauración democrática (1990-2010), Tesis doctoral, Universidad de Leiden, Leiden. 2016.

Jobet, Julio, El Partido Socialista de Chile. Tomo I. Santiago de Chile: Ediciones Prensa Latinoamericana, 1971.

Jobet, Julio, El Partido Socialista de Chile. Tomo II, Santiago de Chile, Ediciones Prensa Latinoamericana, 1971

McCoy, Jennifer, "Political learning and redemocratization in Latin America", Paper presentado en el XIX Congreso Internacional del Latin American Studies Association, Washington DC, 1995.

Moraga, Fabio, “¿Un partido indoamericanista en Chile? La Nueva Acción Pública y el Partido Aprista Peruano (1931-1933)”, Histórica, No. 2, Vol. XXXIII, 2009, p.109-156.

Moulián, Tomás, "Evolución histórica de la izquierda chilena. Influencia del marxismo", FLACSO Documento de Trabajo, No. 139, pp.1-54, 1982.

Moulián, Tomás, "El Marxismo en Chile: Producción y Utilización”, José. J. Brunner, Martín Hopenhayn, Tomás Moulián, y Ludolfo Paramio (Eds.), Paradigmas de conocimiento y práctica social en Chile, Santiago de Chile, FLACSO, 1993, pp. 107-161.

Moyano, Cristina, La seducción del poder y la juventud. Una aproximación desde la bistoria a la cultura política MAPU 1969-1973. Tesis de Magíster, Santiago de Chile, Universidad de Santiago de Chile, 2002.

Muñoz, Víctor, "El Partido Socialista de Chile y la presente cultura de facciones. Un enfoque histórico generacional (1973 - 2015)", Revista Izquierdas, Santiago de Chile, No.26, 2016. 
Norambuena, Carmen, "Exilio y retorno. Chile 1973-1994”, En Mario Garcés y Myriam Olguín (Edits.), Memoria para un nuevo siglo: Chile, miradas a la segunda mitad del siglo XX, Santiago de Chile, LOM Ediciones, 2000.

Ominami, Carlos, "De la ideología a la política", Revista Chile América, No. 78-79, pp.15-19, 1982.

Ortega, Luis "La radicalización de los socialistas de Chile en la década de 1960", Revista Universum, No. 23, Vol..2, Talca, 2008, pp.152-164.

Partido Socialista de Chile, "Crisis de la izquierda según el pleno clandestino de los socialistas de Chile”, Revista Cbile América, Roma, No.78-79, 1982.

Pérez, Cristián, "Compañeros, a las armas: combatientes chilenos en Centroamérica (19791989)", Estudios Públicos, No 129, 2013, pp-141-164.

Perry, Mariana, La dimensión internacional del pensamiento político cbileno. Aprendizaje y transferencia en el exilio, Leiden, tesis para optar al grado de Doctor, Universidad de Leiden, 2016.

Politzer, Patricia, Altamirano. Buenos Aires, Grupo Editorial Zeta, 1989.

Pollack, Benny, "The Chilean Socialist Party: Prolegomena to Its Ideology and Organization", Journal of Latin American Studies, No.1, Vol. 10, Cambridge, 1978, p.117-152.

Pollack, Benny y Hernan Rosenkranz, Revolutionary social democracy: the Chilean socialist party, Nueva York, St. Martin's Press, 1986.

Puryear, Jeffrey, Thinking politics: intellectuals and democracy in Chile, 1973-1988, Baltimore, Johns Hopkins University Press. 1994.

Riquelme, Alfredo, Rojo atardecer: el comunismo chileno entre dictadura y democracia, Santiago de Chile, Centro de Investigaciones Diego Barros Arana, 2009.

Roberts, Kenneth, "Renovation in the Revolution? Dictatorship, Democracy, and Political Change in the Chilean Left", Working Paper, No. 203, Notre Dame, Helen Kellogg Institute for International Studies, 1994, pp. 1-36.

Roberts, Kenneth, Deepening Democracy? The modern Left and Social Movements in Chile and Peru, Stanford, Stanford University Press, 1998.

Rojas, Jorge y Manuel Loyola (Eds.), Por un rojo amanecer: hacia una historia de los comunistas chilenos, Santiago, The Author, 2000.

Rojas, Mauricio, La Renovación de la izquierda cbilena durante la dictadura, Santiago de Chile, Piso Diez Ediciones, 2017.

Silva, Patricio, "Social Democracy, Neoliberalism and Ideological Change in the Chilean Socialist Movement, 1973-1992”, en XVII Congreso Internacional LAS A, California, 1992.

Ulianova, Olga, "La Unidad Popular y el golpe Militar en Chile: percepciones y análisis soviéticos”, Estudios Públicos, No. 79, 2000.

Ulianova, Olga, "Inserción internacional del socialismo chileno 1933-1973". En Olga Ulianova

(Ed.), Redes políticas y militancias. La bistoria política está de vuelta, Santiago de Chile, Ariadna Ediciones, 2009.

Ulianova, Olga, "Relaciones internacionales y redefiniciones en el socialismo chileno, 19731979”, Revista Irquierdas, No., 4, pp. 1-30, 2009.

Ulianova, Olga, "La nueva inserción internacional del comunismo chileno tras el golpe militar", En Alfredo Riquelme y Tania Harmer (Edits.), Chile y la Guerra Fría global, Santiago de Chile, RIL Editores, 2014.

Valderrama, Miguel," Renovación Socialista y Renovación Historiográfica”, PREDES Debates y Reflexiones. Aportes para la investigación social, Santiago de Chile, No.5, 2001.

Vargas, María de los Ángeles y Lucila Díaz, Del golpe a la división. Historia del Partido Socialista 1973-1979. Tesis de Licenciatura, Santiago de Chile, Universidad ARCIS, 2007.

Vergara, Jorge, "El pensamiento de la izquierda chilena en los sesenta. Notas de investigación”, En Augusto Varas, Alfredo Riquelme y Marcelo Casals (Edits.), El Partido Comunista en Chile. Una bistoria presente (185-226), Santiago de Chile, Editorial Catalonia Ltd, 2010. 
1979.

Viera-Gallo, José Antonio, "Renovar la izquierda", Revista Chile América, Roma, No., 50-51,

Wolpin, Miles, "La influencia internacional de la Revolución Cubana: Chile, 1958-1970", Foro Internacional, Vol. 12, No, 4 (48), Colegio de México, 1972, pp. 453-496.

Yocelevsky, Ricardo, "El Partido Socialista de Chile bajo la dictadura militar", Revista Foro Internacional, No. 105, vol.21, México D.F, julio-septiembre 1986, p. 105

Fuentes electrónicas

Altamirano. Carlos, "Informe del Secretario General Camarada Carlos Altamirano al Pleno extraordinario del Comité Central del Partido Socialista". Berlín, 1978. Documento extraído de Partido Socialista de Chile: www.socialismo-chileno.org, en 2015.

Altamirano, Carlos, "Mensaje a los socialistas de Chile", Berlín, junio de 1977. Documento extraído del sitio web http.www.socialismo-chileno.org, visitado el 15 de septiembre de 2015.

Dirección Interior. Partido Socialista de Chile. Al calor de la lucha contra el fascismo, construir la fuerza dirigente del pueblo para asegurar la victoria!. Santiago de Chile, Marzo, 1974. Documento extraído de http.www.socialismo-chileno.org, visitado en septiembre de 2015. 